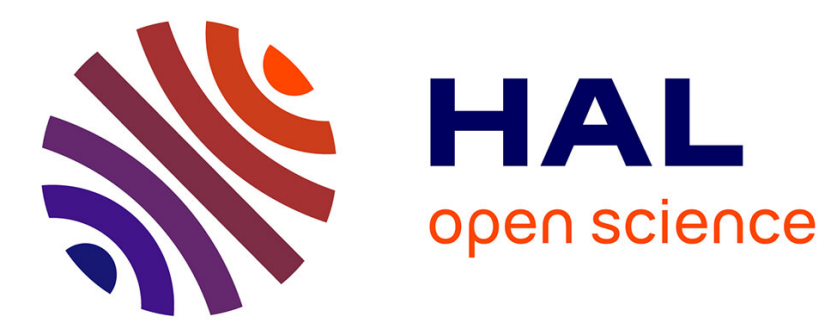

\title{
Improving the Spectral Analysis of Hydrological Signals to Efficiently Constrain Watershed Properties
}

\author{
Jonathan Schuite, Nicolas Flipo, Nicolas Massei, Agnès Rivière, Fulvia
}

Baratelli

\section{- To cite this version:}

Jonathan Schuite, Nicolas Flipo, Nicolas Massei, Agnès Rivière, Fulvia Baratelli. Improving the Spectral Analysis of Hydrological Signals to Efficiently Constrain Watershed Properties. Water Resources Research, 2019, 55 (5), pp.4043-4065. 10.1029/2018WR024579 . hal-02194344

HAL Id: hal-02194344

https://hal-normandie-univ.archives-ouvertes.fr/hal-02194344

Submitted on 1 Sep 2021

HAL is a multi-disciplinary open access archive for the deposit and dissemination of scientific research documents, whether they are published or not. The documents may come from teaching and research institutions in France or abroad, or from public or private research centers.

$$
\text { Copyright }
$$

L'archive ouverte pluridisciplinaire HAL, est destinée au dépôt et à la diffusion de documents scientifiques de niveau recherche, publiés ou non, émanant des établissements d'enseignement et de recherche français ou étrangers, des laboratoires publics ou privés. 


\section{Water Resources Research}

\section{RESEARCH ARTICLE \\ 10.1029/2018WR024579}

Key Points:

- Hydrological responses to climatic forcing can be described more efficiently by new transfer functions (TFs)

- The new TFs account for flow in three key hydrosystem compartments (surface, vadose zone, and aquifer) to interpret data in the spectral domain

- The use of previously derived TFs may lead to severe misestimation of catchment dynamics and properties, like aquifer hydraulic diffusivity

Supporting Information:

- Supporting Information S1

Correspondence to:

J. Schuite,

jonathan.schuite@mines-paristech.fr

Citation:

Schuite, J., Flipo, N., Massei, N., Rivière, A., \& Baratelli, F. (2019). Improving the spectral analysis of hydrological signals to efficiently constrain watershed properties. Water Resources Research, 55, 4043-4065. https://doi.org/10.1029/ 2018WR024579

Received 13 DEC 2018 Accepted 2 APR 2019

Accepted article online 9 APR 2019 Published online 15 MAY 2019

\section{Improving the Spectral Analysis of Hydrological Signals to Efficiently Constrain Watershed Properties}

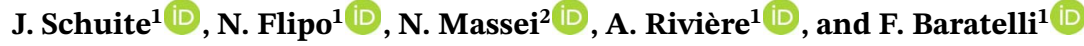 \\ ${ }^{1}$ Centre de Géosciences, MINES ParisTech, PSL Université Paris, Fontainebleau, France, ${ }^{2}$ Laboratoire de \\ Morphodynamique Continentale et Côtiére, UMR-CNRS 6143 M2C, Université Rouen-Normandie, Mont Saint-Aignan, \\ France
}

\begin{abstract}
The footprint of catchment properties on water flow is reflected into hydrological signals, such as stream discharge. Here we demonstrate that it is possible to constrain catchment properties from the spectral analysis of hydrological signals but only when an appropriate transfer function (TF) is used for interpretation. We show that the appropriate theoretical TF, newly derived, is the only one to robustly describe a large diversity of experimental TFs that could be encountered in nature, because it entails the role of diffuse overflow and flow through the vadose zone, which have never been considered in spectral approaches before. The properties that may be estimated are the characteristic time scales of transfer in each compartment (surface, vadose zone, and aquifer) and the flow partitioning between surface and subsurface. We validate our approach by comparing the new and previous theoretical TFs to experimental TFs generated by a physically based distributed hydrological model, for a wide range of properties. The results confirm that without the use of the new TF, the interpretation of observed spectra may often lead to severe misestimations of catchment properties. The potential of the new $\mathrm{TF}$ to constrain catchment characteristics is exemplified by analyzing real hydrological signals from two watersheds with distinct behaviors. We finally discuss the broad implications of our findings and how they may contribute to a variety of topics in hydrology, thereby opening the way to a more widespread and robust use of spectral analysis to describe hydrosystems from effective rainfall, river discharge, and piezometric data.
\end{abstract}

Plain Language Summary Time series of hydrological variables, such as river discharge rates or groundwater levels, are very different from the rainfall signal that feeds continental hydrosystems. In addition, different watersheds undergoing similar climatic conditions do not produce similar hydrological responses. Therefore, deciphering how a climatic signal is altered and retranscribed into hydrological signals is a difficult task. Nevertheless, understanding how hydrosystems react to different time scales of climatic forcing remains an important challenge for water management, as it is key to predicting extreme hydrological events (severe droughts and floods). Here we develop and validate a new approach to study the impact of various hydrological compartments (such as surface waters or subsurface waters) on climatic signal transformation. We use a spectral domain approach, meaning that river discharge, for instance, is not seen as function of time but rather as a function of the various elementary frenquencies that compose the signal. We demonstrate that our new approach favors the interpretation of data in the spectral domain and thereby enhances comprehension of flow processes in response to different time scales of climatic inputs.

\section{Introduction}

Hydrosystems are continental entities that host freshwater resources on which ecosystems and society depend. They form an architectured multipath environment for water, from rainfall to sea (Dooge, 1968; Flipo et al., 2014). For any hydrosystem, the main factor controlling freshwater quantity is climate, which determines the amount of effective precipitation feeding the hydrological compartments (i.e., rivers, lakes, biosphere, aquifers, and unsaturated soils; Milly, 1994). In turn, the physical properties and organization of these compartments, as well as their degree of connection, modulate the distribution and dynamics of water flow. In nature, hydrosystems are heterogeneous and display a broad variety of internal properties and flow transfer processes, resulting in large differences in observed hydrological responses (i.e., stream flow rate and piezometric levels) between catchments undergoing similar climatic conditions (Figure 1; e.g., Slimani
(C)2019. American Geophysical Union. All Rights Reserved. 


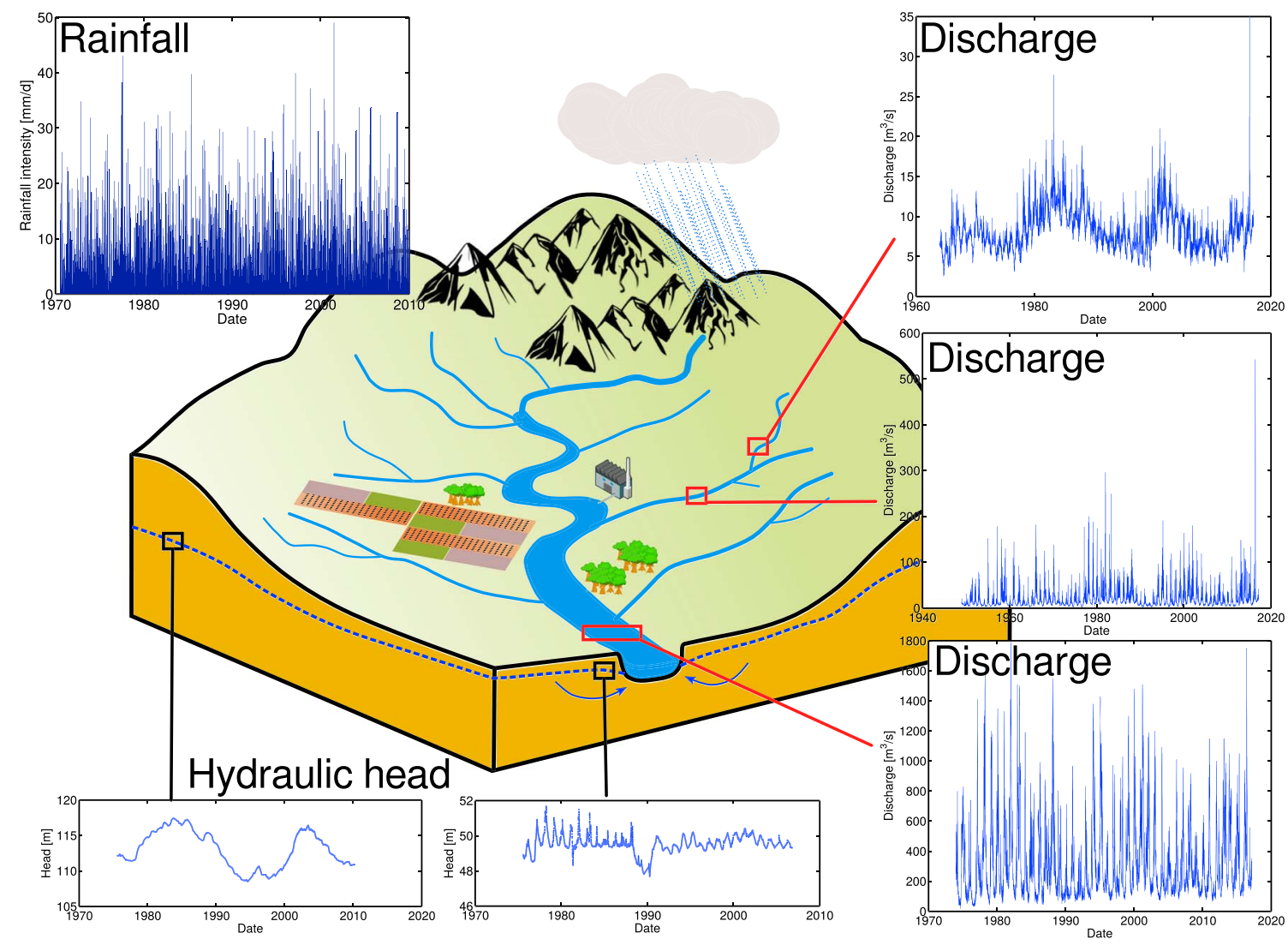

Figure 1. (a) Meshed geometry of the catchment used for the Catchment Water Quality Simulator simulations. (b) Organizational chart of the transfer functions that are compared to the synthetic data generated with Catchment Water Quality Simulator. The various mathematical symbols refer to those used for the TF derivations presented in section 2. Note that "f" stands for "function of."

et al., 2009). Due to such a considerable variability, deciphering how a climatic signal is propagated through a hydrosystem, or more precisely, how it is altered and retranscribed into hydrological signals, is a difficult task (Cloke \& Hannah, 2011). Nevertheless, being able to understand how catchments react to the different time scales of climatic forcings remains an important challenge for water management, as it is key to predicting extreme hydrological events such as severe droughts, floods, or water quality degradation (e.g., Barco et al., 2010; Chevalier et al., 2014; Ducharne et al., 2007; Jiménez-Martínez et al., 2016; Massei \& Fournier, 2012; Massei et al., 2017; McGuire \& McDonnell, 2006). Conversely, analyzing and linking climatic data (i.e., rainfall and potential evapotranspiration) to hydrological data may provide valuable firsthand information on the overall properties and functioning of a hydrological basin (Jiménez-Martínez et al., 2013; Labat et al., 2000; Manga, 1999; Molénat et al., 1999; Pedretti et al., 2016; Weiler et al., 2003).

Commonly, hydrologists gain knowledge on the properties of a catchment by interpretation of collected data with models that entail their conceptualization of the system's functioning. Strategies range from simple lumped modeling to more complex physically based distributed models, each having its perks and flaws (Devia et al., 2015; Fatichi et al., 2016; Jakeman \& Hornberger, 1993). Model parameters are adjusted so that they may reproduce the observations with the highest fidelity possible, through an operation known as "calibration" (e.g., Gupta et al., 2005). However, the vast majority of calibration procedures are performed in the time domain, meaning that the computed time series are compared to the observed time series. In comparison, the studies focusing on the interpretation of data in the spectral domain seem much less numerous (e.g., Gelhar, 1974; Jiménez-Martínez et al., 2013, 2016; Kirchner et al., 2001; Manga, 1999; Montanari \& Toth, 2007; Pedretti et al., 2016). Although these studies proved insightful to characterize the temporal scaling of some hydrosystems, we argue that the widespread use of spectral analysis to systematically estimate catchment properties has been prevented by at least three issues: (1) as we will show, the currently available analytical models derived in the spectral domain often fail to explain some of the spectral structures found in hydrological observations, which can be very diverse. Rendering such spectral features (e.g., scale 
invariance ranges) is however fundamental, as these are linked to the physical characteristics of hydrosystems; (2) with previous models, it is not possible to separately identify the dynamics of the three most basic hydrosystem compartments: the surface, the vadose zone, and the saturated zone. Nonetheless, determining where and how fast the water flows is a central topic in hydrology; (3) the impact of some assumptions behind spectral interpretation of data has never been assessed, potentially refraining some hydrologists from using these methods.

In this paper, we address these three issues. First, we will briefly recall the fundamental concepts of spectral analysis in hydrology and the associated theoretical developments (transfer functions) initiated by Gelhar (1974) to describe the climatic signal transformation by catchments. Based on these previous developments, we then introduce a new and alternative approach in order to overcome the issues linked to currently available transfer functions. In particular, we add the possibility to account for diffuse overland flow, as well as the flow through the vadose zone, which have never been considered before in transfer function (TF) approaches. Then, we assess the ability of the new and previously developed TFs to capture the behavior of hydrosystems with distinct properties, by comparing all TFs to the outputs of a pseudo-3-D distributed hydrological model. We further exemplify the added value of the new TF by interpreting discharge and hydraulic head data pertaining to the Seine basin (Northern France). Finally, we discuss the broad implications of our results in the framework of hydrological data interpretation, hydrosystem characterization, and flow modeling.

\section{Frequency Domain Modeling of River Discharge and Hydraulic Head}

\subsection{Founding Concepts and Previous Developments}

One way of evaluating how a physical system transforms an input signal is to use spectral analysis (also named frequency domain or Fourier analysis). Essentially, it differs from the more traditional standpoint where one investigates the evolution in time of a natural signal. With spectral analysis, the point of view is changed so that a signal $g(t)$ is viewed as a theoretically infinite sum of elementary periodic components with different amplitudes, expressed by the Fourier transform (Priestley, 2003):

$$
\tilde{g}(v)=\int_{-\infty}^{+\infty} g(t) e^{-2 \pi i v t} \mathrm{~d} t,
$$

where $i^{2}=-1$ and $v$ is the frequency [1/T]. Note that the tilde $(\sim)$ refers to a variable in the Fourier domain.

We may treat flow through a hydrosystem as a random process under the hypothesis of linearity, stationarity, and system invariance (i.e., the physical properties do not change in time). Then, the observed output $O(t)$ (discharge or piezometric level) is a temporal convolution of the input $I(t)$ (effective rainfall or recharge) by the impulse response function (Olsthoorn, 2008). This is formulated as

$$
O(t)=\int_{-\infty}^{+\infty} F_{\mathrm{io}}(\tau) I(t-\tau) \mathrm{d} \tau,
$$

where $F_{\text {io }}$ stands for the impulse response function, which is basically the filter function. This is rather convenient because in the Fourier domain, equation (2) reads as the product

$$
\tilde{\mathrm{O}}(v)=\tilde{F}_{\mathrm{io}}(v) \tilde{I}(v)
$$

The latter equation lies at the foundation of spectral analysis of physical systems, since the idea is to characterize the filter function $\tilde{F}_{\text {io }}(v)$ that best describes the transformation of the input into an output. The power of spectral analysis, compared to modeling in the time domain, is that the entire data set (input-output) can be interpreted all at once and as a whole, making the approach stochastic rather than deterministic (Gelhar, 1974; Russian et al., 2013). Hence, one may directly take advantage of the intrinsic statistical power of long time series (Olsthoorn, 2008), without the need to correctly simulate each particular event (i.e., flood, low flow or drought).

In a universal way, hydrological basins act as low-pass filters (e.g., Massei \& Fournier, 2012; Zhang \& Schilling, 2004). In other words, low-frequency climatic signals tend to be unaltered and retranscribed "as is" into hydrological observations. This case would typically concern multidecadal climate cycles, but depending on the physical characteristics of the system, variability on scales as low as interannual can also be left almost unchanged. High-frequency signals, however, are degraded and filtered out by hydrosystems. The 


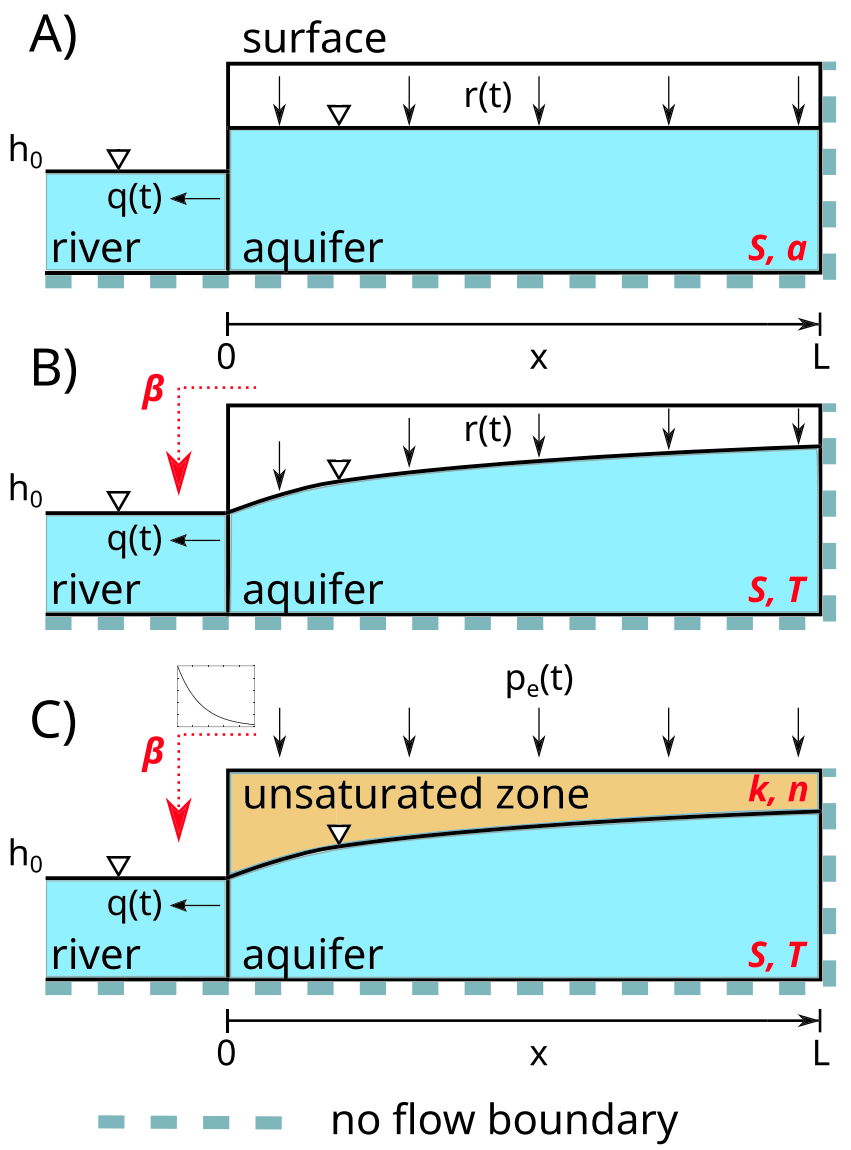

Figure 2. Model settings: (a) linear reservoir model (LR), (b) Linear Dupuit model with a rapid overflow component (LDrun, or LD if $\beta=0$ ), and (c) new model (HYMIT). Key parameters associated to each compartment are noted in red. Adapted from Gelhar (1974) and Russian et al. (2013). way high-frequency components are degraded, as well as the frequency band affected by this transformation, is primarily controlled by the physical properties of a catchment (Gelhar, 1974; Molénat et al., 1999; Russian et al., 2013).

In order to understand the link between flow processes and the spectral response of hydrosystems, several authors derived analytical solutions of widely used flow equations in the Fourier domain (Gelhar, 1974; Molénat et al., 1999; Russian et al., 2013). These solutions, referred to as TFs, have been applied to interpret the spectra of either discharge or piezometric data and describe well the low-pass filtering behavior of hydrosystems. TFs correspond to the squared modulus of the filter function $\tilde{F}$ io $(v)$ in equation (3). Gelhar (1974) founded the basis of the methodology by formulating the mathematical tools describing the frequency domain response of stream discharge and piezometry to groundwater recharge. For example, Manga (1999) showed that the TFs derived by Gelhar are useful to easily estimate the characteristic time scale of aquifer response from effective rainfall and river discharge data. Seemingly, the frequency domain analysis of hydrological variables was also applied to infer the scaling of hydrodynamical and transport properties in diverse hydrosystems (Jiménez-Martínez et al., 2013; Kirchner et al., 2001; Pedretti et al., 2016; Zhang \& Schilling, 2004). These developments revealed the potential richness of information that could be mined in the spectral structure of hydrological variables. Hereafter, we recall some of the concepts and theoretical TFs introduced by Gelhar (1974) and Molénat et al. (1999) that we deem important to understand the approach we subsequently derive. 2.1.1. The LR

The linear reservoir model (LR) is conceptualized in Figure 2a, after Gelhar (1974). It is the simplest view of a 0-D aquifer system draining a uniform recharge input to a stream with the behavior of a leaking basket that has some storage capacity. It is described by (Gelhar, 1974)

$$
S \frac{\mathrm{d} h(t)}{\mathrm{d} t}+q(t)=S \frac{\mathrm{d} h(t)}{\mathrm{d} t}+a\left[h(t)-h_{0}\right]=r(t),
$$

where $S$ is the aquifer storativity (-), $a$ the recession constant $(1 / \mathrm{T}), h(t)$ is the water level in the reservoir at time $t(\mathrm{~L}), q(t)$ is the specific discharge out of the reservoir at time $t(\mathrm{~L} / \mathrm{T})$, and $r(t)$ is the specific recharge rate at time $t(\mathrm{~L} / \mathrm{T})$. In this model, the hydraulic head is independent of the distance from the river $x$ (Gelhar, 1974). Moreover, $h_{0}$, the reference water level in the stream is set to 0 for simplification but without loss of generality, given that we are interested in fluctuations around the mean of stationary processes.

In the case of the LR model, Gelhar (1974) found that the TFs of groundwater recharge to hydraulic head on the one hand (subscript "rh"), and of groundwater recharge to stream discharge (subscript "rq") on the other hand, are respectively expressed by

$$
\left|\tilde{\Theta}_{\mathrm{rh}}(v)\right|^{2}=\left(4 \pi^{2} v^{2} S^{2}+a^{2}\right)^{-1}
$$

and

$$
\left|\tilde{\Theta}_{\mathrm{rq}}(v)\right|^{2}=\left[\left(\frac{2 \pi v S}{a}\right)^{2}+1\right]^{-1} .
$$

In this model, the characteristic hydraulic time scale is defined as

$$
t_{D}=\frac{2 \pi S}{a}
$$

\subsubsection{The LD}

In the classical Dupuit approximation for groundwater flow (Figure 2b), with a uniform source term, the vertical flow is assumed negligible compared to large-scale horizontal flow. However, unlike the LR model, 
it is a finer representation of flow processes in the deep water-saturated subsurface. The linear Dupuit model (LD) along the spatial dimension $x$ reads

$$
S \frac{\partial h(x, t)}{\partial t}=T \frac{\partial^{2} h(x, t)}{\partial x^{2}}+r(t)
$$

with $T$ the transmissivity of the aquifer $\left(\mathrm{L}^{2} / \mathrm{T}\right)$. Following Gelhar (1974), we apply a Dirichlet boundary condition where the aquifer meets the stream and a Neuman boundary condition at the limit of the domain such as

$$
h(x=0, t)=0
$$

and

$$
\frac{\partial h(x=L, t)}{\partial x}=0 .
$$

The length $L$ represents the distance between the river and the Neuman boundary as depicted in Figure $2 \mathrm{~b}$. Hence, for the LD model and with these boundary conditions, Gelhar (1974) derived the associated TF of recharge to hydraulic head, given by

$$
\left|\tilde{\Psi}_{\mathrm{rh}}(x, \nu)\right|^{2}=\left|\frac{1}{2 \pi i v S}\left[1-\frac{\cosh [\kappa(x-L)]}{\cosh [\kappa(L)]}\right]\right|^{2}
$$

with

$$
\kappa=\sqrt{\frac{2 \pi i v S}{T}} .
$$

In turn, the $\mathrm{TF}$ of recharge to discharge is expressed as

$$
\left|\tilde{\Psi}_{\mathrm{rq}}(\nu)\right|^{2}=\frac{T}{2 \pi \nu S L^{2}}|\tanh (\kappa L)|^{2} .
$$

Furthermore, L. W. Gelhar and Wilson (1974) show that by equivalence with the LR model

$$
a=\frac{3 T}{L^{2}} .
$$

Furthermore, the hydraulic time scale in this model is defined as

$$
t_{D}=\frac{2 \pi S L^{2}}{T}=\frac{2 \pi L^{2}}{D}
$$

where $D$ is the aquifer hydraulic diffusivity $\left(\mathrm{L}^{2} / \mathrm{T}\right)$. Note that these solutions were extended for double continuum (multiple porosity) aquifers by Russian et al. (2013). While for the sake of clarity and conciseness we will only use the LD model derived by Gelhar (1974), it is worth noticing that the developments of Russian et al. (2013) could complement our approach, exposed later in this article, without further difficulty.

2.1.3. The Dupuit Model With a Rapid Component to River Discharge (LDrun)

Molénat et al. (1999) present a formulation for the Dupuit model in which they add the effect of a rapid overflow component to river discharge. This component may either be interpreted as surface runoff or as rapid groundwater flow such as in karstic cavities. Essentially, a fraction $\beta$ of the input flux is allowed to reach the river immediately (Figure 2b). In mathematical terms, in the Fourier domain, this is formulated as

$$
\tilde{q}(v)=\tilde{\Psi}_{\mathrm{rq}}(v) \tilde{r}(v)+\beta \tilde{p}_{\mathrm{e}}(v),
$$

where $\tilde{p}_{\mathrm{e}}(v)$ is the effective precipitation. At this point, Molénat et al. (1999) make the rather strong assumption that $\tilde{r}(v)=(1-\beta) \tilde{p}_{\mathrm{e}}(\nu)$ and they find a new TF $\left|\tilde{\Psi}_{\text {mol }}(v)\right|^{2}$ expressed as

$$
\left|\tilde{\Psi}_{\mathrm{mol}}(v)\right|^{2}=\left|\frac{\tilde{q}(v)}{\tilde{p}_{\mathrm{e}}(v)}\right|^{2}=\left[\tilde{\Psi}_{\mathrm{rq}}(v)(1-\beta)+\beta\right]\left[\tilde{\Psi}_{\mathrm{rq}}^{*}(v)(1-\beta)+\beta\right] .
$$

Here the asterisk denotes the complex conjugate. 


\subsection{A New Framework for Large Hydrosystems (HYMIT)}

Although the aforementioned studies provided undeniable advances to the characterization of hydrosystem properties from the most common hydrological data, caution should be taken when using currently available TFs. For instance, analyzing discharge data with the TFs of Gelhar (1974) or Russian et al. (2013) implies that the entire volume of water drained by the river transits solely through aquifer compartments. This implicitly discards any surface flow process, which in many cases would constitute a strong hypothesis. Therefore, Molénat et al. (1999) were the first to enrich Gelhar's approach by introducing a rapid overflow component in the calculation of the TFs. However, these authors assumed that the contribution of surface flow to the total discharge is immediate, meaning that any drop of water falling on a waterhsed is transferred to the river with a time inferior to the data sampling time step (typically a day). When this assumption could be realistic for small catchments, it becomes limiting for larger basins encompassing a dense river network. Another important limitation of current approaches, which concerns both discharge and piezometric data interpretation, is that the flow through the vadose zone is not taken into account. Yet the unsaturated zone is an important hydrological compartment whose effect on flow within hydrological basins is often not negligible, especially when aquifers are overlied by thick soils (Cao et al., 2016; Harter \& Hopmans, 2004).

Based on previous studies, presented above, we derive a new TF that we call HYMIT, for HYdrological MInimalist TF. HYMIT accounts for (1) the transfer from effective rainfall to groundwater recharge through the unsaturated layer, (2) flow through a Dupuit aquifer, and (3) a diffuse overflow component (Figure 2c). The representation of flow through the vadose zone is formalized by the Nash cascade (or reservoirs in series; 1959), which is a satisfying first-order approximation of transfer processes in soils (Besbes \& De Marsily, 1984; Cao et al., 2016; Wu et al., 1997). It is similar to a Gamma distribution (Kirchner et al., 2000).

In this case, the recharge rate $r(t)$ is a temporal convolution of a fraction $1-\beta$ of the effective rainfall $p_{\mathrm{e}}(t)$ so that

$$
r(t)=(1-\beta) \int_{-\infty}^{+\infty} \Phi(\tau) p_{\mathrm{e}}(t-\tau) \mathrm{d} \tau,
$$

where $\Phi(t)$ is the impulse response function characterizing how the unsaturated zone transforms the rain signal into recharge as follows (Besbes \& De Marsily, 1984)

$$
\Phi(t)=\frac{1}{k(n-1) !}\left(\frac{t}{k}\right)^{n-1} e^{-t / k},
$$

where $n$ is the number of Nash reservoirs and $k$ is the reservoir emptying constant (T). For the purpose of demonstration, we may rewrite equation (19) such as

$$
\Phi(t)=\frac{s^{n}}{(n-1) !} t^{n-1} e^{-s t},
$$

with $s=k^{-1}$. The Fourier transform of $\Phi(t)$ is then derived (Appendix A), yielding

$$
\tilde{\Phi}(v)=\frac{s^{n}}{(2 \pi i v+s)^{n}} .
$$

This impulse response function is similar to-or even a generalization of-the LR model in the sense that at low frequency, it tends to 1 , and it degrades the signal for high frequency. The more reservoirs, the more the signal is degraded at high frequency. Therewith, equation (18) can be rewritten in the Fourier domain such as

$$
\tilde{r}(v)=(1-\beta) \tilde{\Phi}(v) \tilde{p}_{\mathrm{e}}(v)
$$

We may now enhance the Molénat model (equation (16))

$$
\tilde{q}(v)=(1-\beta) \tilde{\Phi}(v) \tilde{\Psi}_{\mathrm{rq}}(v) \tilde{p}_{\mathrm{e}}(v)+\beta \tilde{\Omega}(v) \tilde{p}_{\mathrm{e}}(v)
$$

In this manner, we overcome the strong assumption of Molénat et al. (1999) that effective rainfall equals recharge, by directly accounting for the flow dynamics through the unsaturated zone. For very large basins, we expect the typical runoff average transit time to be greater than 1 day, which is in general the time step used to sample river discharge. Hence, this is why we introduce in equation (23) the additional impulse response function $\tilde{\Omega}(v)$ to account for the delay between surface runoff generation and transfer to the main 
river. Here we chose a simple exponential decay TF to account for the diffuse time distribution of surface flow (hence similar to LR) expressed as

$$
\Omega(t)=\lambda e^{-\lambda t} .
$$

In the Fourier domain, this yields

$$
\tilde{\Omega}(v)=\frac{\lambda}{2 \pi i v+\lambda} .
$$

The parameter $\lambda\left(\mathrm{d}^{-1}\right)$ is the recession constant of the exponential reservoir and may be interpreted as the mean surface concentration time or surface transit time to the outlet. Hence, it controls the persistence of runoff. We may now formulate the new TF of effective rainfall to discharge, HYMIT, such as

$$
\left|\tilde{\chi}_{\mathrm{pq}}(v)\right|^{2}=\left|\frac{\tilde{q}(v)}{\tilde{p}_{\mathrm{e}}(v)}\right|^{2}=\left|\tilde{\Phi}(v) \tilde{\Psi}_{\mathrm{rq}}(v)(1-\beta)+\beta \tilde{\Omega}(v)\right|^{2} .
$$

From here, it is straightforward to build the equivalent TF of effective rainfall to hydraulic head. We have

$$
\tilde{h}(v)=\tilde{\Psi}_{\mathrm{rh}}(v) \tilde{r}(v),
$$

and given equations (11) and (22), we find

$$
\left|\tilde{\chi}_{\mathrm{ph}}(x, v)\right|^{2}=\left|\frac{\tilde{h}(x, v)}{\tilde{p}_{\mathrm{e}}(v)}\right|^{2}=\left|\frac{(1-\beta) \tilde{\Phi}(v)}{2 \pi i v S}\left[1-\frac{\cosh [\kappa(x-L)]}{\cosh [\kappa(L)]}\right]\right|^{2} .
$$

One may see that $\left|\tilde{\chi}_{\mathrm{ph}}(x, v)\right|^{2}$ tends to 0 toward the boundary $x=0$. When the aquifer is always connected to the river, when the fluxes are always directed from groundwater to stream water, and when the level of the river's free surface has negligible fluctuations compared to piezometric heads, this representation might be acceptable. However, most natural cases do not meet this configuration, as river-aquifer interfaces often display more complex dynamics varying in both space and time (Flipo et al., 2014). It is therefore recommended to use equation (28) only to analyze piezometers located far enough from the river-aquifer interface-that is to say—at a distance where the Dupuit-Forchheimer assumptions are satisfied (e.g., Morel-Seytoux, 2009).

\subsection{Comparison of the TFs}

Note that for comparison purposes between all theoretical TFs, we assume that $r(t)=p_{e}(t)$ for LR and LD and $r(t)=(1-\beta) p_{e}(t)$ for LD model with an added rapid overflow component (LDrun; Molénat et al., 1999). Moreover, in the remainder of the manuscript, all references to rainfall will implicitly invoke the effective rainfall $p_{e}$. This is to alleviate verbosity whenever convenient.

The TFs described above may be expressed as a function of dimensionless frequency, which is obtained by dividing the frequency by a critical frequency $v_{c}$ (unit $\left[\mathrm{T}^{-1}\right]$ ) that depends on model parameters describing the aquifer properties (Figure 3). It is simply expressed as $v_{c}=t_{D}^{-1}$ (equation (7) for LR and equation (15) for the three other models). All TFs reach a horizontal asymptote at low frequency (typically for $v / v_{c}<$ $<1$ ). As expected from their mathematical expressions, the rainfall-discharge TFs tend to 1 , whereas rainfall-piezometric level TFs tend to distinct values depending on the chosen parameter set. At middle and high frequency, TFs decrease with frequency, reflecting the low-pass filtering behavior of hydrosystems. The only exception is the LDrun rainfall-discharge TF, which also tends toward a plateau at high frequency. This is because the rapid runoff fraction strongly reduces autocorrelation between and within quick flow events (only for LDrun), thereby maintaining high energy in high-frequency components.

From this perspective, one may already note two interesting features concerning HYMIT. First, it displays the same overall behavior as the LR model for rainfall-discharge, given the chosen parameters, but it differs largely from this very same model when considering the rainfall head responses. This means that a joint analysis of well and discharge data using TFs may greatly improve parameter estimations where the aquifer unit may be considered homogeneous. As we will demonstrate in the following, this also denotes the high explanatory power of HYMIT.

Second, HYMIT is less sensitive to the rapid overflow parameter than its counterpart LDrun. Here the fractions of overflow are the same $\beta=0.4$ (Figure 3), but HYMIT results in a much larger energy decay at high frequency than LDrun. As a consequence, the HYMIT model may be applied to hydrosystems that display a strong energy decay with frequency but where substantial overflow is expected. 
a)

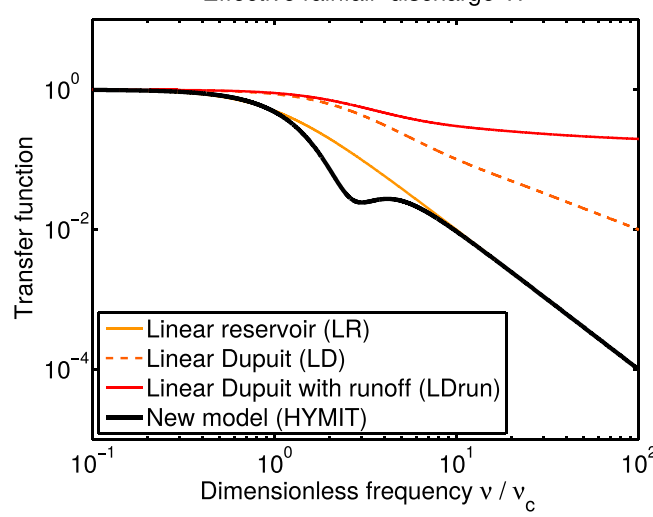

b)

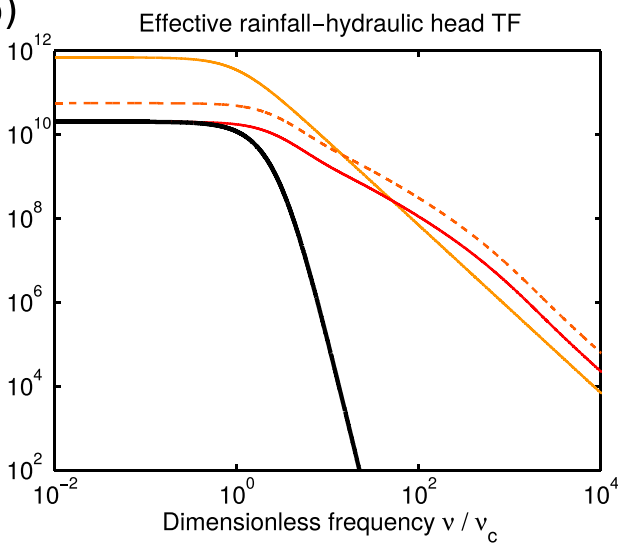

Figure 3. (a) Effective rainfall-discharge transfer functions. (b) Effective rainfall-hydraulic head transfer functions. Parameters: $\beta=0.4$ for LDrun and HYMIT and $\lambda=0.1$ day $^{-1}, n=4$, and $k=8$ day for HYMIT. Transfer functions for hydraulic head are computed for $x=L / 10$. All transfer functions are represented as a function of dimensionless frequency, as the frequency $v$ is here normalized by (1) $v_{c}=a /(2 \pi S)$ for LR and (2) $v_{c}=T /\left(2 \pi S L^{2}\right)$ for LD, LDrun, and HYMIT.

\section{Evaluating the Performance of TF Approaches}

\subsection{Aims, Benefits, and Novelty of the Evaluation}

We have proposed a new TF describing the climatic signal alteration by idealized hydrosystems according to their physical properties. In the following section, a pseudo-3-D physically based model (Catchment Water

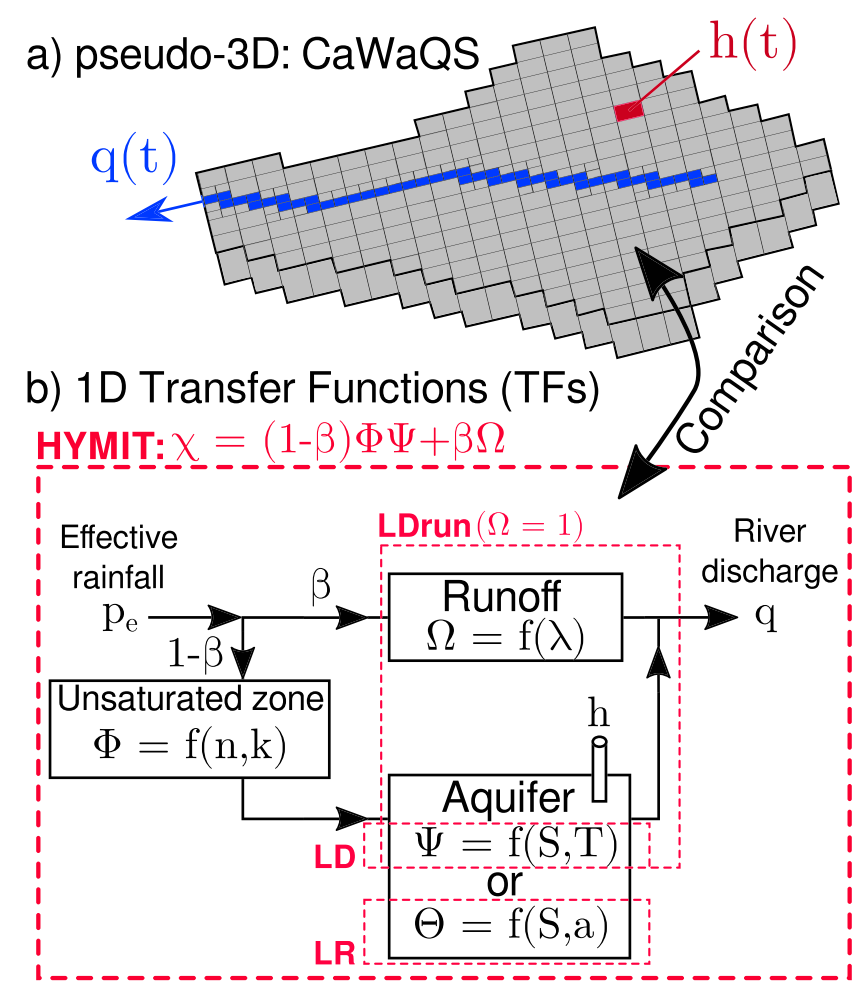

Figure 4. (a) Meshed geometry of the catchment used for the CaWaQS simulations. (b) Organizational chart of the transfer functions that are compared to the synthetic data generated with CaWaQS. The various mathematical symbols refer to those used for the TF derivations presented in section 2. Note that " $\mathrm{f}$ " stands for "function of." CaWaQS = Catchment Water Quality Simulator. HYMIT $=$ HYdrological MInimalist LDrun = linear Dupuit with runoff; LD = linear Dupuit; LR = linear reservoir.
Quality Simulator [CaWaQS]) is implemented to generate synthetic data sets (discharge and piezometry) for a qualitative evaluation of all TFs. We explore parameter sets representative of various catchment behaviors (see section 3.2). This evaluation consists in strictly comparing TFs to the generated data sets (Figure 4). Hence, it is important to note that in this section, the TFs are not at all adjusted (or "fitted") to the synthetic data. The goals of such an evaluation are the following:

1. As we use CaWaQS to perform forward modeling in this case, we may test a variety of parameter sets and test their influence on the spectral response of hydrological data. Thereby, we may evaluate the ability of TFs to capture the flow scaling under various hydrological conditions and predict the influence of each functional compartment on the spectral structure of hydrological data.

2. CaWaQS performs pseudo-3-D flow calculations and may therefore help to constrain the impact of the $1 \mathrm{D}$ geometry represented by TFs.

3. CaWaQS entails nonlinear flow behaviors such as reservoir thresholds or river-aquifer flux exchanges and may thus be used to assess the impact of the assumptions underlying TF developments (see section 2.1), which to the best of our knowledge has never been performed before.

4. Comparing TFs to the outputs of CaWaQS in the spectral domain is a way to evaluate the most satisfactory method to process data before interpretation (see section 3.3).

\subsection{Distributed Model and Strategy of Evaluation}

In this section, we present the strategy developed to compare the TFs to the outputs obtained from the distributed physically based hydrological model CaWaQS (Figure 4a). It has the same structure and functioning as the EauDyssée platform described by Baratelli et al. (2016), Flipo et al. (2012), Pryet et al. (2015), and Saleh et al. (2011), which stems from the native code MODCOU (Ledoux et al., 1984). CaWaQS combines several modules that, together, simulate flow through hydrosystems: 
- The surface mass balance module separates precipitation into actual evapotranspiration, surface runoff, infiltration, and soil storage. It is tuned by seven parameters. For this study, it is important to note that the surface runoff in CaWaQS has two components: an immediate transfer-to-river component and a hypodermic flow component approximated by a reservoir with exponential drainage. We inhibited the immediate component in this study. Hence, the coefficient of recession of the hypodermic flow is here similar to the parameter $\lambda$ in HYMIT.

- The river flow module is based on a Muskingum scheme (David et al., 2011). However, to establish a proper correspondence with the TF approach, the river routing module was here tuned to act as a simple drain: once surface and subsurface fluxes reach the river, they are summed up on a daily basis to constitute the daily total river discharge. This way, the only parameter controlling diffusion of surface flow is the recession coefficient of hypodermic flow. Consequently, the detailed physics of river flow are not explicitly taken into account. Nonetheless, river-aquifer exchanges can happen in both directions and are controlled by the riverbed conductivity, which is here fixed to $10^{-6} \mathrm{~m} / \mathrm{s}$ and head difference between river and aquifer. The river water level is calculated in each river cell using the Manning formula as explained by Baratelli et al. (2016).

- Flow through the unsaturated zone is conceptualized by a succession of reservoirs (Nash cascade), just like in the HYMIT model.

- The saturated groundwater flow module numerically solves the 2-D diffusivity equation to compute hydraulic heads (finite difference scheme). Vertical fluxes from the unsaturated zone are treated as source terms.

The geometry of the CaWaQS model chosen for comparison is depicted in Figure 4a. Its shape is random, but it constitutes a plausible representation of a natural catchment. The modeling configuration is set so that it is conceptually close enough to the various hypothesis underlying the development of the TFs presented in the previous section. It is composed of a unique river draining the whole basin. One single, uniform, and isotropic aquifer covers the entire subsurface. It has a confined behavior at all points. The boundary and initial conditions are as follows: zero flux at the domain's limits (Neuman BC) and initial hydraulic head is set to $10 \mathrm{~m}$ above the ground surface, in order to ensure that the aquifer is hydraulically connected to the river at the beginning of the simulations. All simulations were performed in transient mode over a 40 -year time period.

The input time series of precipitation and potential evapotranspiration were taken from the SAFRAN database, which includes distributed meteorological data over France since 1970 on $8 \times 8 \mathrm{~km}^{2}$ grid (Quintana-Segui et al., 2008). For the sake of simplicity, we chose to extract the daily rainfall and evapotranspiration time series of one specific cell in the SAFRAN mesh. The chosen cell is approximately in the center of the Seine basin (Northern France) and is thereby assumed to be sufficiently representative of most temperate oceanic climates. This climatic input is applied homogeneously over the entire modeled catchment. The effective precipitation time series are then computed from the surface balance module implemented in CaWaQS and constitutes the reference input throughout this work.

Here we present six representative test cases labeled A to F. Each case, or simulation, is assigned a different parameter set (Table 1), thereby entangling end-member situations. With cases A to D, we aim at testing the influence of hydraulic diffusivity and the impact of the unsaturated zone. Therefore, the two first simulations (A and B) differ only in aquifer properties: B diffuses pressure signals much faster than $\mathrm{A}$. Cases $\mathrm{C}$ and $\mathrm{D}$ mirror the same conditions than A and B, except for the unsaturated zone which has a stronger influence (higher $k$ and $n$ ). Finally, $\mathrm{E}$ and $\mathrm{F}$ are intermediate situations with a higher impact of diffuse runoff than in the previous cases. These six simulations are not sufficient to draw a full sensitivity analysis, which is not the aim of the paper. Instead, we show the main features of TFs approaches and validate their use on these end-member examples.

\subsection{Processing of Experimental Outputs Obtained From $\mathrm{CaWaQS}$}

The river discharge at the outlet of the catchment, the surface water balance, and the hydraulic head at 1 node (Figure 4a) are retrieved from the simulation outputs in order to perform our analysis. Transformation of discrete time series into the spectral domain is known to be accompanied by artifacts, such as spectral leakage, sensitivity to sampling, and round off errors in the fast Fourier transform (FFT) which add noise (Blank et al., 1971; Jiménez-Martínez et al., 2013). The effect of such artifacts can be limited by the use of regularization techniques (smoothness enforcement), windowing, multiple overlapping, and detrending 


\begin{tabular}{|c|c|c|c|c|c|c|}
\hline \multirow[b]{2}{*}{ Case } & \multicolumn{6}{|c|}{ Parameter (unit) } \\
\hline & $D\left(\mathrm{~m}^{2} / \mathrm{s}\right)$ & $t_{D}$ (years) & $\beta(\%)$ & $n$ & $k$ (day) & $1 / \lambda$ (day) \\
\hline A & 20 & 220 & 23 & 1 & 2 & 10 \\
\hline B & 2,000 & 2.2 & 23 & 1 & 2 & 10 \\
\hline $\mathrm{C}$ & 20 & 220 & 23 & 4 & 25 & 10 \\
\hline $\mathrm{D}$ & 2,000 & 2.2 & 23 & 4 & 25 & 10 \\
\hline E & 120 & 37 & 39 & 7 & 30 & 15 \\
\hline $\mathrm{F}$ & 300 & 15 & 72 & 5 & 12 & 38 \\
\hline
\end{tabular}

(Blank et al., 1971; Jiménez-Martínez et al., 2013; Long \& Derickson, 1999; Neuman \& De Marsily, 1976; Welch, 1967). However, once applied on actual data, it is difficult to evaluate which combination of processing techniques performs best. Here we computed the discrete Fourier transform of the detrended time series of precipitation and simulated discharge and hydraulic head. We also tapered the signals with a Hann window, which enhances the resolution in FFT calculations when a broad range of component strengths at different frequency is expected (Harris, 1978). As a result, we obtain the power spectrum densities (PSD) of our times series and we calculated the experimental TF with the simple relation (Pedretti et al., 2016):

$$
\mathrm{TF}_{\mathrm{ex}}=\frac{\mathrm{PSD}_{\mathrm{h}}}{\mathrm{PSD}_{\mathrm{pe}}}
$$

which corresponds to a deconvolution in the time domain. The subscripts $h$ and pe refer to the hydrological variable (discharge or head) and the effective rainfall, respectively. Additionally, we enforced smoothness of all experimental TFs by computing a simple moving average.

\subsection{Results}

\subsubsection{Discharge Output Analysis}

We show in Figure 5 the comparison between the experimental TFs of discharge over effective precipitation obtained from CaWaQS and the different theoretical TFs. We observe that the large diversity in hydrosystem properties tested does not result in a wide diversity in the general shape of experimental TFs. In general, the latter presents a plateau at low frequency and a strong decreasing trend at high frequency, where autocorrelation in the discharge signal comes into play. It is at midrange frequency, where a transition between the plateau and sharp slope occurs, that the various TFs display most of their differences. Another major difference is the ordinate position of the low-frequency plateau. For high characteristic groundwater diffusion times $\left(t_{D}<40\right.$ years), the plateau stabilizes around 1, which is the theoretical horizontal asymptote for all rainfall-discharge TFs (see section 2.3). For lower groundwater diffusion times, the low-frequency plateau is never reached due to a period of simulation that is too short compared to $t_{D}$.

By observing these results (Figure 5), we may formulate the following general remarks:

1. The newly developed HYMIT model is the only one that captures all the shapes of the experimental TFs over a wide range of frequencies and for all simulations. It also displays sensitivity to small fluctuations in the spectra.

2. For long groundwater response times (cases A, C, E, and F), the LR, LD, and LDrun models systematically fail to reproduce a large portion of the spectra.

3. When the effect of the vadose zone is given a strong influence by increasing parameters $n$ and $k$ (simulations $\mathrm{C}, \mathrm{D}$, and E), it shows its signature by an energy depletion in the midfrequency range $\left(1.10^{-3}<\right.$ $v<1.10^{-2}$ day $^{-1}$ ). HYMIT is able to capture such singularity reasonably well. However, we note that the effect of the unsaturated zone is not detectable when the overflow is high (case F), which makes sense in the way that the less water is available for the subsurface, the less impact it has on the observed spectra. Our tests confirm that the unsaturated zone may or may not have a significant imprint on the structure of experimental spectra, depending on the other parameters, but HYMIT correctly represents the complex interplay between processes.

In the particular case of simulation $\mathrm{B}$, the spectral tail of the discharge signal for $v>2.10^{-3}$ day $^{-1}$ is mainly controlled by diffuse runoff and aquifer flow, because the vadose zone is tuned to have only little effect 

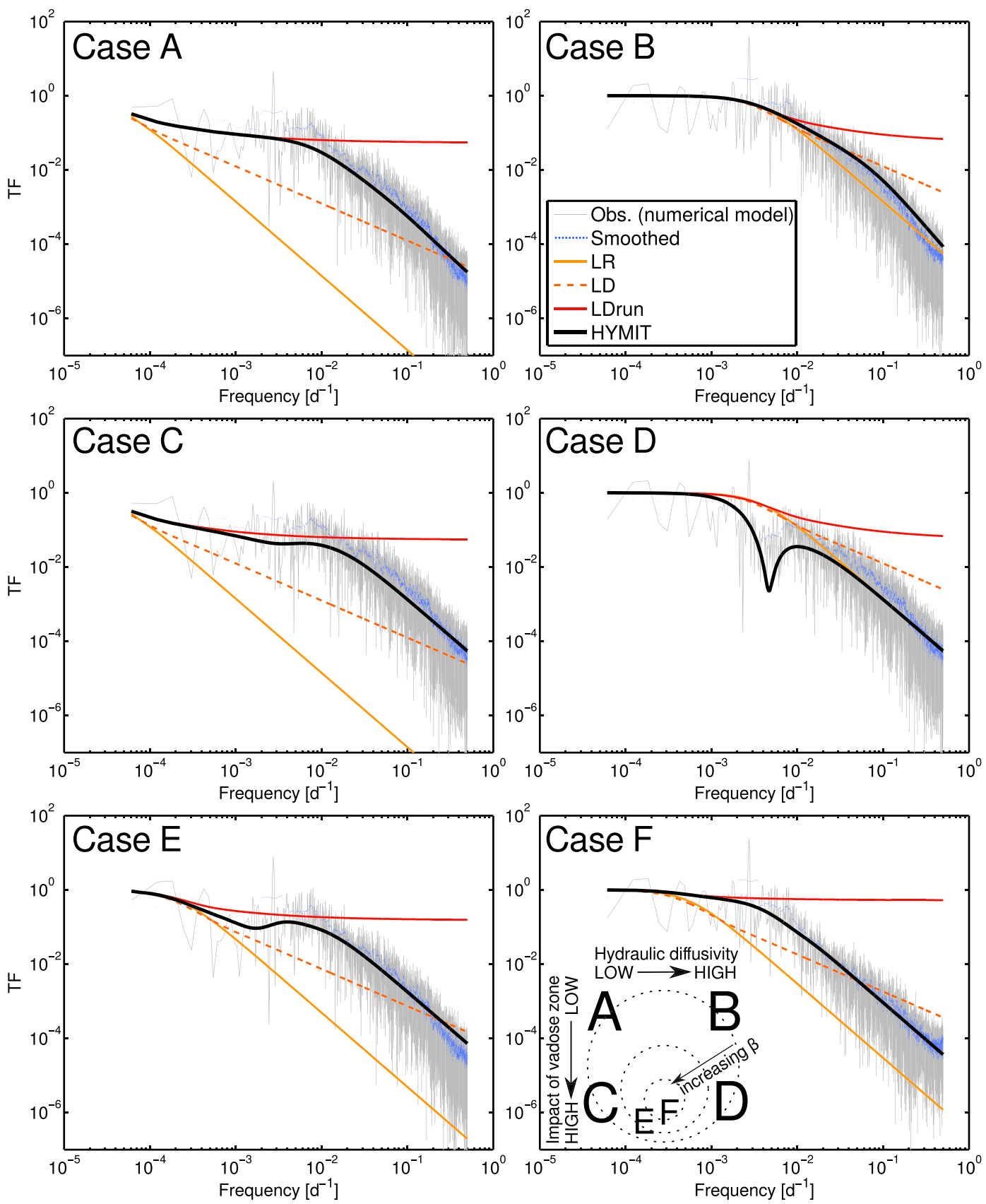

Figure 5. Comparison of effective rainfall-discharge experimental transfer functions obtained from simulations with CaWaQS and theoretical transfer functions (no fitting or adjustments). The inset in the graph of case $\mathrm{F}$ is a visual reminder and synthesis of each case's properties (the dashed circles represent the scale for $\beta$ ). LR = linear reservoir; LD = linear Dupuit; LDrun = linear Dupuit with runoff; HYMIT = HYdrological MInimalist Transfer function.

(Table 1). Hence, for $2.10^{-3}<v<2.10^{-2}$ day $^{-1}$, the tail's structure is primarily controlled by groundwater flow because LR and LD show approximately the same amplitudes, but for higher frequencies, the runoff process is overriding. Surface runoff has a linear reservoir behavior, which is why LR is still reasonably accurate in high-frequency ranges. Here HYMIT seizes very well the transition between the competing processes across frequencies, which is not surprising given it is build upon the LD and LR models. It is a confirmation that the HYMIT model is coherent and well structured.

Furthermore, we notice that in simulation F, the HYMIT model almost perfectly matches the shape of the LR model, but both TFs do not overlap because they represent different processes (Figure $4 \mathrm{~b}$ ). In this 

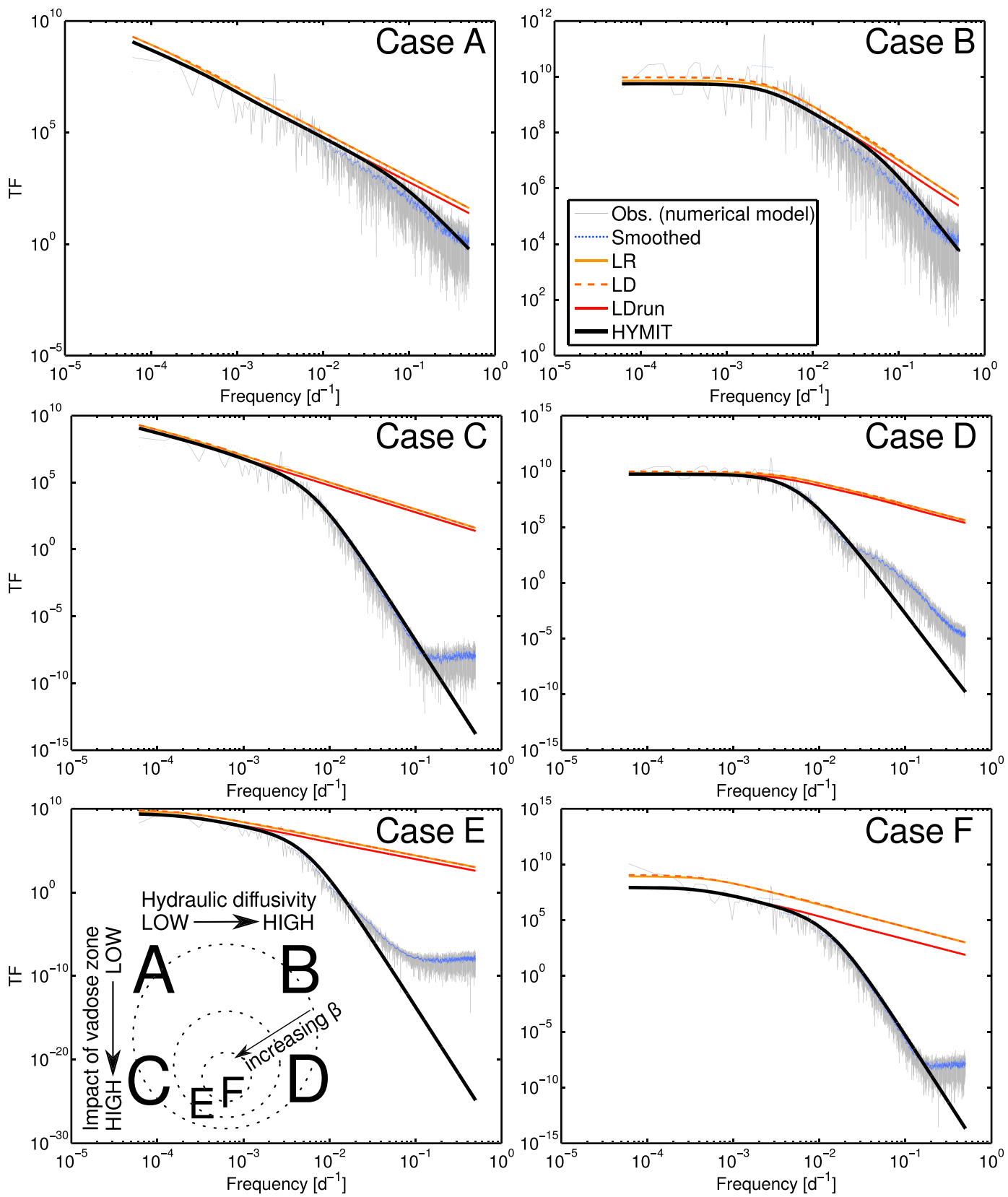

Figure 6. Comparison of effective rainfall-hydraulic head experimental transfer functions obtained from simulations with CaWaQS and theoretical transfer functions (no fitting or adjustments). The monitoring position of hydraulic head is $x \simeq L / 2$. The inset in the graph of case $\mathrm{E}$ is a visual reminder and synthesis of each case's properties (the dashed circles represent the scale for $\beta$ ). LR = linear reservoir; LD = linear Dupuit; LDrun = linear Dupuit with runoff; HYMIT $=$ HYdrological MInimalist Transfer function.

simulation, the impact of diffuse runoff is so strong that it hides the footprint of subsurface compartments almost completely.

\subsubsection{Hydraulic Head Output Analysis}

The experimental TFs of rainfall-hydraulic head display a more noticeable diversity in shape compared to the rainfall-discharge TFs, especially when the vadose zone is well developed (Figures 6c-6f). This is an indication that the variability of piezometric signals is much more sensitive to hydrological conditions and system properties than river discharge rates. At low frequency, the various experimental TFs are well explained by all TFs, with the exception of LR and LD when $\beta$ is high (cases E and F). The transition between low and high frequency is reasonably well captured by LR, LD, and LDrun only when the effect of the unsaturated zone 


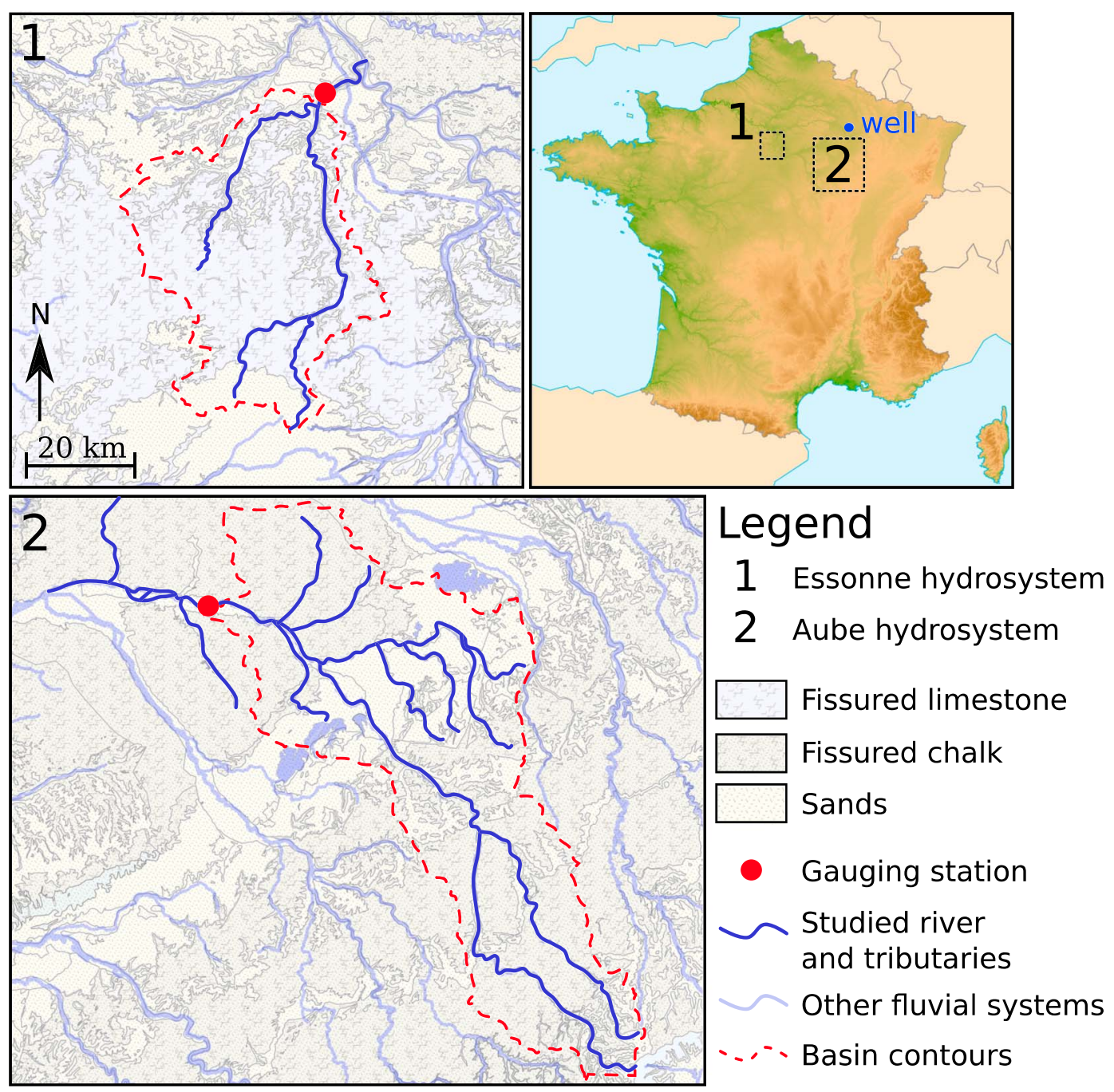

Figure 7. Location and context of the Essonne and Aube fluvial hydrosystems.

is limited (thus, only for cases A and B). For all simulations, HYMIT reproduces this transition very well. In particular, HYMIT is able to explain a large part of the sigmoidal shape found in the TFs of simulations C to $\mathrm{F}$, where other theoretical TFs do not match observations at all.

The observed spectra are not explained by any models at high frequency in simulations $\mathrm{C}$ to $\mathrm{F}\left(v>0.1 \mathrm{day}^{-1}\right.$; Figure 6). In fact, the smoothing effect of the vadose zone in these simulations might be so efficient that the calculation of the FFT could be strongly affected at high frequency by the preponderance of numerical noise. In other words, the aquifer and vadose zone efficiently remove all high-frequency content in the piezometric signal. Yet computationally, the FFT algorithm is still able to find very low amplitude signals in the high-frequency range $\left(v>0.1\right.$ day $\left.^{-1}\right)$, within numerical errors which have no hydrological meaning. This explains the mismatch in simulations $\mathrm{C}, \mathrm{E}$, and F. However, numerical noise issues may not explain the larger deviation observed in case $\mathrm{D}$, which occur at energies of hydrological relevance. Instead, this deviation might be the signature of a process that is represented in CaWaQS, but not in any of the theoretical TFs, such as bioriented river-aquifer exchanges (or in other words, a temporarily alternating losing and gaining river).

\section{Application to the Spectral Analysis of Real Hydrological Data}

\subsection{Presentation of Sample Data}

In order to illustrate the potentials of HYMIT to characterize real hydrosystems, we test its use on two different sample discharge rate data sets. Here we consider two French rivers, the Essonne and the Aube, both draining subbasins of the larger Seine hydrosystem (Northern France) (Billen et al., 2007; Pryet et al., 2015). 

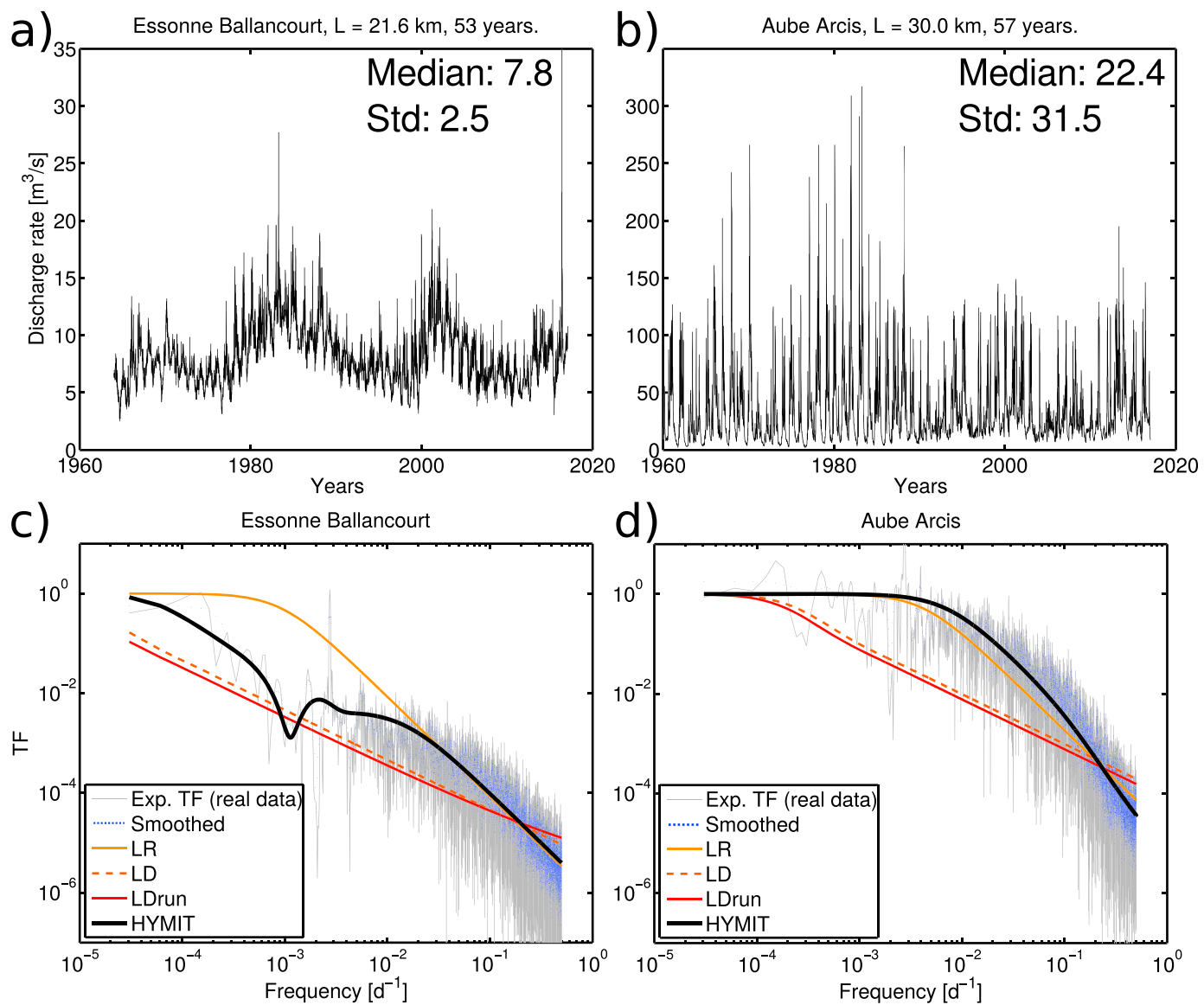

Figure 8. Discharge rate time series of the Essonne River (a) and Aube River (b) forming part of the larger Seine basin hydrosystem. Location of gauging stations is shown in Figure 7. "Median" and "Std" stand for median value and standard deviation of discharge over the period $\left(\mathrm{m}^{3} / \mathrm{s}\right)$. Comparison of rainfall streamflow experimental transfer functions, (c) Essonne and (d) Aube, and best matching theoretical transfer functions from the Monte Carlo sampling procedure $\mathrm{TF}=$ transfer function; $\mathrm{LR}=$ linear reservoir; $\mathrm{LD}=$ linear Dupuit; $\mathrm{LDrun}=$ linear Dupuit with runoff; HYMIT $=$ HYdrological MInimalist Transfer function.

Time series of discharge rate are collected from the Ballancourt-sur-Essonne and Arcis-sur-Aube gauging stations, respectively (Figure 7). These two examples are chosen because

1. The available time series cover a long period of time (more than 50 years; Figure 8).

2. The watersheds display distinct hydrological behaviors. The flow rate of the Essonne is characterized by a strong low-frequency component and relatively small amplitude of the annual component (Figure 8). It is the contrary for the Aube river (Figure 8).

3. The watersheds present significant differences in lithology. The Essonne drains limestone and sand formations (Oligocene), whereas the Aube basin consists of Cretaceous chalk and clay units, as well as Jurassic limestones and marls in its uphill part (Figure 7).

4. The Essonne basin is twice smaller than the Aube basin, draining 1,870 and $3,590 \mathrm{~km}^{2}$, respectively. This might be one of the main reasons that we observe an order of magnitude difference between discharge peaks for these two rivers (Figure 8).

We also analyzed the data from one well pertaining to the Marne basin (Figure 7) which is presented in the supporting information. All three basins are mainly occupied by agricultural landscapes, leaving few space for urban areas (less than 10\%).

\subsection{Model Adjustment Procedure}

The experimental TFs of the Essonne and Aube river flow rates are very different in shape, reflecting the a priori distinct hydrological conditions mentioned previously (Figure 8). 
Table 2

Effective Rainfall-Discharge TF's Parameter Sets Performing Best for the Aube and the Essonne Rivers (50,000 Monte Carlo Samplings)

\begin{tabular}{|c|c|c|c|c|c|c|c|c|}
\hline \multirow[b]{2}{*}{ River/Model } & \multicolumn{8}{|c|}{ Parameter (unit) } \\
\hline & $L(\mathrm{~km})$ & $D=T / S\left(\mathrm{~m}^{2} / \mathrm{s}\right)$ & $t_{D}$ (years) & $\beta(\%)$ & $n$ & $k$ (day) & $1 / \lambda$ (day) & $\overline{\text { RMSLE }}$ \\
\hline Essonne & 21.6 & & & & & & & \\
\hline $\mathrm{LR}^{\mathrm{a}}$ & & 10.5 & 9 & - & - & - & - & 0.86 \\
\hline $\mathrm{LD}^{\mathrm{b}}$ & & 0.16 & 582 & - & - & - & - & 1.13 \\
\hline LDrun $^{\mathrm{c}}$ & & 0.11 & 846 & 0.1 & - & - & - & 1.26 \\
\hline HYMIT $^{\mathrm{d}}$ & & 0.92 & 100 & 7 & 9 & 43 & 11 & 0.76 \\
\hline Aube & 30.0 & & & & & & & \\
\hline $\mathrm{LR}^{\mathrm{a}}$ & & 93.5 & 2 & - & - & - & - & 1.08 \\
\hline $\mathrm{LD}^{\mathrm{b}}$ & & 6.4 & 28 & - & - & - & - & 1.76 \\
\hline LDrun $^{\mathrm{c}}$ & & 5.0 & 36 & 0.0 & - & - & - & 1.78 \\
\hline HYMIT $^{\mathrm{d}}$ & & 3476.5 & $5 \times 10^{-2 \mathrm{e}}$ & 24 & 1 & 20 & 30 & 0.80 \\
\hline
\end{tabular}

Note. The associated RMSLE (equation (30)) is also shown. $\mathrm{TF}=$ transfer function; $\mathrm{LR}=$ linear reservoir; $\mathrm{LD}=$ linear Dupuit; LDrun = linear Dupuit with runoff; HYMIT = HYdrological MInimalist Transfer function.

${ }^{a}$ Computed from equations (6) and (14). ${ }^{b}$ Computed from equation (13). ${ }^{c}$ Computed from equation (17). ${ }^{d}$ New model.

Computed from equation (26). ${ }^{\mathrm{e}}$ About 19 days.

Theoretical TFs were adjusted to the regularized experimental TFs using a simple Monte Carlo parameter space sampling method (50,000 runs). The quality of each simulation is assessed by a root-mean-square error (RMSLE) cost function expressed as

$$
\text { RMSLE }=\sqrt{\frac{1}{N} \sum_{i=1}^{N} \log \left(\frac{E_{i}}{O_{i}}\right)^{2}},
$$

where $E_{i}$ and $O_{i}$ are the estimated (theoretical) and observed (experimental) values and $N$ the number of values.

\subsection{Results}

As expected by its demonstrated flexibility, the HYMIT model explains best the two experimental TFs of rainfall-discharge at all frenquencies (Figures $8 \mathrm{c}$ and 8d). The Essonne case study illustrates the power of the HYMIT model, which is the only one capable of properly representing the complex shape of the power spectrum at all frequencies. The other TFs capture only partially the complex dynamics of the river. For the Aube, the LR model satisfactorily matches the spectrum but it is not able to capture the curvature at midfrequency $\left(5.10^{-3}<v<2.10^{-1}\right.$ day $\left.^{-1}\right)$ as reliably as HYMIT.

The parameters obtained for the best fit between model and data are grouped in Table 2. From these results, we observe that the contribution of surface overflow to stream discharge differs by an order of magnitude for the two studied catchments. Indeed, the Aube flow rate is significantly fed by surface runoff $(\beta=0.24)$, which has a long characteristic diffusion time $(1 / \lambda=30$ day) according to the HYMIT model. The hydraulic diffusivity $D=T / S$ is also found to be largely different between these hydrosystems. For the Essonne, $D$ is on the order of $1 \mathrm{~m}^{2} / \mathrm{s}$, whereas for the Aube, the estimation is nearly $4.10^{3} \mathrm{~m}^{2} / \mathrm{s}$. Finally, the impact of flow in the unsaturated zone is very significant for the Essonne ( $n=9$ and $k=43$ day) and weak for the Aube $(k=1$ day and $n=20)$.

\section{Discussion}

\subsection{HYMIT: A Powerful Tool to Understand Global Hydrosystem Characteristics From Data} Analysis

5.1.1. Linking Spectral Signatures to Hydrosystem Physical Properties and Flow Processes

As pointed out by several authors in earlier works (Jiménez-Martínez et al., 2013, 2016; Manga, 1999; Molénat et al., 1999), we have shown that the analysis of hydrological data in the spectral domain is a rapid and straightforward way of estimating the scaling properties of a hydrosystem. Nevertheless, we have 
demonstrated that the theoretical TFs used by these authors often severely fail to describe experimental TFs from a simplified regional hydrosystem model, yet comprising the most fundamental flow compartments (surface, vadose zone, and aquifer).

On the contrary, the newly developed TF, HYMIT, is able to reproduce a large variability of hydrological conditions and thereby a large variety of observed TFs. It gives a physical meaning to detailed features in the spectrum, such as the localized intensity loss for $1.10^{-3}<v<1.10^{-2}$ day $^{-1}$ in case D (Figure 5), which is the signature of an important influence of the vadose zone. This feature is also observed on actual data (Figure 8). Hence, not only does HYMIT integrate a more complete and realistic set of flow characteristics but it also displays a real sensitivity to detailed features in experimental spectra. Consequently, one now has the opportunity to relate these important spectral features to actual flow processes and actual physical parameters of the system, such as aquifer hydraulic diffusivity or the fraction of infiltration versus overflow, using one single and unified set of TFs.

Another important feature of HYMIT is that it is based on the LD model to represent the transfer in the saturated zone. Yet to the best of our knowledge, the LD model alone is not a popular choice to interpret data. Instead, the LR model is more often used because experimental spectra generally display a spectral tail nearly in $v^{-2}$ in rainfall-discharge analysis. However, one could argue that to represent flow in an aquifer, the LD model is physically more consistent than LR. It is in fact often tempting to fit the LR model to experimental TFs, like in case F in Figure 5, but then, the estimated time response would be that of the catchment as a whole. In turn, it would be impossible to tell how the different compartments contribute to the watershed's global response. For example, Manga (1999) discussed how the LR model could be used to infer $t_{D}$. In light of our work, what the author claims to be the hydraulic time scale might well be the time response of a catchment as a whole, not only that of the aquifer compartment. When such a doubt arises, our new solution (HYMIT) is able to differentiate the influence of each key hydrosystem compartment on its global characteristic response time.

Hence, HYMIT accounts for both physical consistency in aquifer flow dynamics and allows for the interpretation of experimental data with tails having a slope ranging between -3 and 0 in log-log plots, which is usually observed in data (Figures 8c and 8d; Labat et al., 2002; Matsoukas et al., 2000; Schilling \& Zhang, 2012; Slimani et al., 2009). Such capability alone makes HYMIT a much more powerful tool than LR and LD, which, by construction, always exhibit slopes of -2 and -1 , respectively, and therefore are incapable of matching real data $\mathrm{TF}$.

\subsubsection{Validity of Underlying Hypotheses in TF Approaches}

The mathematical derivations of the TFs presented in this paper are only valid under the hypothesis of process linearity, process stationarity, and system invariance because convolution and Fourier transformation are used as founding basis to TF approaches. For sure, natural flow processes in real hydrosystems are nonlinear. Hydrological data display to some extent a nonstationary component under a changing climate, and landscapes are evolving at decade scales by anthropic activities (agriculture, urbanization, etc.) and thereby surface properties may vary with time. Nonetheless, as CaWaQS is a physically based model handling nonlinear flow dynamics, we saw that the assumption of linearity has only a limited impact in the cases presented, given that HYMIT reproduces well the experimental TFs. This assertion seems valid for the broad range of hydrosystem properties that we tested.

Next, for the time series stationarity to be respected in the weak sense, the first and second moment of precipitation and hydrological variable must remain constant over time (Jiménez-Martínez et al., 2013). In hydrology, nonstationarity arises when the studied time frame is too short, that is, when the longest observable natural climatic oscillations are not completely entailed in the frame. In the case of the Seine hydrosystem, for instance, the longest detectable natural climatic cycle is the Northern Atlantic Oscillation, with a period lying between 13 and 20 years (Massei et al., 2010, 2017). Throughout our study, we used at least 40 years of data, thus covering at least two complete Northern Atlantic Oscillation cycles. In doing so, we ensure time series stationarity, at minima for their stochastic component (fluctuations around the mean).

As for property invariance, we have shown that the performance of HYMIT was not significantly compromised by the fact that we took the temporal average of overflow fraction calculated by CaWaQS as the $\beta$ parameter for HYMIT (fixed). Yet this fraction is typically ranging from 0 during dry seasons to a maximum nonzero value during wet seasons. Our results demonstrate that taking a single mean value for $\beta$ is satisfactory in a statistical sense for TF analysis. Nevertheless, if system properties are affected by larger noncyclic 
transformations over the years, property invariance would be probably more compromised and affect the robustness of TF approaches. As an example, this could be the case for small catchments, where the urban area is expending rapidly and significantly (let us say increasing by 1 order of magnitude in percentage of total area).

\subsubsection{Data Processing Method}

Additionally, our tests confirmed that detrending and tapering the signal with a Hann window prior to FFT computation are indeed a satisfactory choice of data processing. We could not get as good an agreement between observed (from numerical experiments) and theoretical TFs without this type of data preparation (not shown here). This is an important point, because methods for treating data prior to spectral analysis are still a matter of debate in various domains and it depends on the application (e.g., Harris, 1978; Jiménez-Martínez et al., 2013; Long \& Derickson, 1999; Neuman \& De Marsily, 1976), but it is known to affect the shape of calculated spectra and thus the targeted parameter estimates. We argue that our benchmarking tests have helped to clarify this debate in the framework of hydrological data analysis.

\subsubsection{Hydrological Significance of Estimated Parameters}

As always in hydrological modeling frameworks, the problem of equifinality arises (Beven, 2006). We used a trivial Monte Carlo sampling procedure to fit theoretical TFs to observed TFs (real data). Albeit many runs were performed, we cannot discard the fact that completely different parameter sets as those obtained in Table 2 could be equally efficient in explaining our data. In this paper, our aim is to illustrate the potentials and limits of TF approaches in hydrology and not to perform a robust model inversion. Nevertheless, we note, in a qualitative way, that there is some coherence in the computed parameters for the Essonne and Aube catchments. Indeed, the Essonne basin entails several wetlands and the river itself is bordered by many ponds, which in average favor infiltration over surface runoff. Hence, the estimated high impact of the unsaturated zone $(n=9)$ and the low runoff fraction $(\beta=0.07)$ are plausible. Seemingly, a large part of the Aube subsurface system consists of poorly permeable units that are often discarded in regional scale modeling (Pryet et al., 2015). It is therefore reasonable that the computed fraction of runoff is significantly higher for the Aube river $(\beta=0.24)$. This low permeability region, if really not efficient to conduct water, would also overshadow the effect of transfer in the vadose zone, which is here found to have a low impact $(n=1)$. These elements of consistency are encouraging in the sense that HYMIT brings coherent first-hand information on hydrosystems that can be useful in the design of more complete and detailed hydrological studies, for instance. Nonetheless, more robust inversion procedures should be tested in this framework in the future.

\subsection{Broader Implications for Hydrological and Transport Modeling in the Framework of Water Resources Management} 5.2.1. From Data to Priors for Hydrological Models

Precipitation, potential evapotranspiration, river discharge, and piezometric time series are by far the most commonly available continuous data sets in hydrology. Climatic data are applied as forcings to distributed hydrological models, and the performance of these models is then evaluated by a comparison of their outputs to observed discharge and piezometric data. The often numerous parameters of a model can be tuned by calibration procedures to minimize the misfit between simulation outputs and data. Such physically based distributed models, such as CaWaQS, are decisive tools in the management of water resources at catchment and regional scales. Among many applications lies the possibility of predicting the evolution of water resources under changing climatic conditions. Nevertheless, hydrological models are subject to the well-known issue of equifinality (Beven, 2006). Besides, model performance is assessed based on several criteria such as the Nash-Sutcliffe or the Kling-Gupta criteria (Gupta et al., 2009; Nash \& Sutcliffe, 1970), bias, or root-mean-square error. These criteria do never tell how well the spectral content of data is reproduced. Hence, retrieving beforehand knowledge on basin's physical properties, by using an integrated TF approach that is informative on actual and usable physical properties, would be a major asset in future hydrological studies. For instance, an important issue at the root of equifinality is that there is yet no objective way to divide precipitated water between surface flow and subsurface flow. Several partitioning ratios, with appropriate parameter tuning, may lead to similar model performances but very different water management schemes. In this framework, we demonstrate that HYMIT has the potential to provide this information from data alone. HYMIT will not be able to reveal the complete temporal and spatial heterogeneities in hydrosystem properties, but it may at least provide tangible estimates of mean parameters and more importantly, it may reveal the role on flow of each fundamental hydrological compartment. Consequently, HYMIT could be used to guide the calibration of distributed models that are necessary tools for integrated water management. 
In this sense, HYMIT could also help focusing on the most realistic dominant processes for a given scale in the framework of physics-based distributed hydrological modeling, following the "Dominant Processes Concept " proposed by Blöschl (2001).

\subsubsection{Link with LSMs}

An interesting potential application of the data analysis underlined in this study concerns Land Surface Models (LSMs). LSMs are agile modeling platforms capable of simulating the distributed energy, water, and biogeochemical mass balances at the soil-vegetation-atmosphere interface (Collischonn et al., 2007; Ducharne et al., 2003; Liang et al., 1994; Masson et al., 2013; Pitman, 2003). They constitute a central component in Global Circulation Models used in climatic studies and forecasts and are also implemented in hydrological studies such as flood forecasting (e.g., Ducharne et al., 2003; Wu et al., 2014). In particular, widely used LSMs are based on state-of-the-art physical concepts for the calculation of evapotranspiration (Pitman, 2003) and are therefore considered the most advanced and precise tools for the estimation of surface energy and water budgets.

Nevertheless, many LSM outputs are routed to the outlet of hydrosystems through a combination of linear reservoirs, emulating the behavior of fast (surface) and slow (subsurface) compartments. For instance, this is the case for the Variable Infiltration Capacity model (Liang et al., 1994, 1996) which is implemented into the SURFEX-ISBA model (Masson et al., 2013), the SECHIBA module of the ORCHIDEE model (Ducharne et al., 2003; Krinner et al., 2005), or the MGB-IPH model (Collischonn et al., 2007; Paiva et al., 2013). In this framework, the analysis of hydrological data with HYMIT could potentially help to calibrate the dynamics of the routing modules in these LSMs, as well as flow partitioning between surface and subsurface drainage thanks to parameter $\beta$. Yet the way information is transferred from HYMIT to LSMs requires further attention, since it is not straightforward to use parameters derived with an averaging model (HYMIT) to a distributed model with variable spatial resolution (LSM). One idea would be to ensure that regionalized LSM parameters correspond to HYMIT parameters. Thereby, the main challenge would be to choose appropriate upscaling operators (e.g., Samaniego et al., 2010).

\subsubsection{Implication for Solute Transport Characterization}

Catchments host a tremendous number of biological and geochemical reactions originating from the natural life cycle, anthropogenic activities, and geological weathering. These reactions span large temporal and spatial scales and are therefore difficult to characterize. The way nutrients, contaminants, or other solutes are produced, stored, and released by catchments is partly controlled by the water cycle and flow dynamics. With the high-frequency measurement of solute concentrations in rivers becoming more and more tractable (Floury et al., 2017), a new vision of watersheds as "reactors" has emerged (Grathwohl et al., 2013). Kirchner et al. (2000, 2001) used spectral analysis of chloride concentration data to demonstrate that small catchments keep releasing solutes over much longer time scales than usually predicted by a simple linear reservoir concept (scaling in $v^{-1}$ instead of $v^{-2}$ for LR). On the opposite for very large basins such as the Amazon, the release of ions is drastically more dampened at high frequency than predicted by the LR model (Bouchez et al., 2017). Seemingly, we have shown in this study that the linear reservoir paradigm describing the behavior of flow for an entire catchment is misguiding and sabotages our ability to properly understand watershed dynamics.

HYMIT presents the opportunity to extract, from the most commonplace hydrological data, the time scale of transfer through three key compartments and the fraction of flow that permeates through soil and rock. Such information is crucial to correctly represent the transport of solutes in a watershed. In particular, HYMIT should help deconvolving the advection part of transport from the reactive and dispersive components or identified preferential pathways (Bouchez et al., 2017; Floury et al., 2018). In a few years, it will be possible to analyze both hydraulic and geochemical data over the same times scales (several decades of data at high frequency) and to potentially refine the conceptualization of catchments as "reactors" (Grathwohl et al., 2013). We argue that a minimalist, yet complete and consistent TF such as HYMIT, will be useful to conduct these future advances.

\section{Conclusion}

We contributed to the study of hydrosystem flow processes in the spectral domain. Based upon previous developments, we derived a new HYMIT that describes the transformation of effective precipitation signals 
into hydrological variables, such as hydraulic head or stream discharge. In our developments, we have explicitly added the effect of diffuse surface runoff and the role of the unsaturated zone on flow to TFs derived in previous studies. The performance of the previous and the new TFs was assessed by a comparison with outputs from a pseudo-3-D distributed hydrological model.

After appropriate data processing, we find that HYMIT is able to describe observed TFs much better than previous TFs, which do not account for all key processes. Thereby, we validated our approach and demonstrated that it may be used to separate the response of different functional compartments of a hydrosystem (surface water, vadose zone, and groundwater processes). From the numerical experiments, along with real data sets, we have shown that experimental TFs display special structures that show sensitivity to flow in each compartment. HYMIT is able to capture in more details such features that can be translated in terms of imprint of a given compartment on the climatic signal transformation. We have shown that discarding the flow in the vadose zone and the effect of diffuse runoff, which was the case in previous approaches, could lead to large errors in parameter estimates, especially for hydraulic diffusivity and hydraulic time scale. Finally, our study suggests that the underlying hypotheses of linearity and stationarity have only a limited impact on the explanatory power of HYMIT.

\section{Appendix A: Fourier Transform of the Nash Cascade Model}

To derive the Fourier transform of the Nash cascade model (equation (20), Nash (1959)), we first rewrite it as

$$
\Phi(t)=s^{n} F_{N}(t)
$$

with $N=n-1$ and

$$
F_{N}(t)=\frac{1}{N !} t^{N} e^{-s t}
$$

We now seek to prove that for any natural $N \geq 0$, we have

$$
\tilde{F}_{N}(v)=\frac{1}{(2 \pi i v+s)^{N+1}} .
$$

We demonstrate that by induction. First, we test this equality by calculating the Fourier transform for $N=0$ :

$$
\tilde{F}_{0}(v)=\int_{0}^{+\infty} \frac{t^{0}}{0 !} e^{-(2 \pi i v+s) t} \mathrm{~d} t=\left[-\frac{e^{-(2 \pi i v+s) t}}{(2 \pi i v+s)}\right]_{0}^{+\infty}=\frac{1}{(2 \pi i v+s)}
$$

This validates the initialization, and we now have to check for heredity

$$
\tilde{F}_{N+1}(v)=\int_{0}^{+\infty} \frac{1}{(N+1) !} t^{N+1} e^{-s t} e^{-2 \pi i v t} \mathrm{~d} t,
$$

which gives

$$
\tilde{F}_{N+1}(v)=\underbrace{\left[-\frac{t^{N+1} e^{-(2 \pi i v+s) t}}{(2 \pi i v+s)(N+1) !}\right]_{0}^{+\infty}}_{A}-\underbrace{\int_{0}^{+\infty} \frac{-t^{N}(N+1)}{(2 \pi i v+s)(N+1) !} e^{-(2 \pi i v+s) t} \mathrm{~d} t}_{B} .
$$

We here need to demonstrate that the term $A$ in equation (A6) reduces to 0 . While it is obvious that for $t=0$, $A=0$, the convergence of $A$ is unclear when $t \mapsto+\infty$. Consequently, we need to prove that the function $f$ defined by

$$
f(x)=x^{\alpha} e^{-x}, \forall x>0 \quad \forall \alpha>0
$$

converges toward 0 when $x \mapsto+\infty$. For that we use the Squeeze lemma. First, $\forall x>0, f(x)>0$. Then we will find a function $g$ such as

$$
\begin{gathered}
\forall x>0, \quad 0<f(x)<g(x), \\
\lim _{x \rightarrow+\infty} g(x)=0 .
\end{gathered}
$$


To build up $g(x)$, we first verify by induction that

$$
\forall p \geq 0 \quad \forall x>0, \quad H_{p}(x)=e^{x}-\frac{x^{p}}{p !}>0 .
$$

For $p=0$, this proposition is true since $\forall x>0, e^{x}-1>0$.

To prove that $\forall x>0, H_{p+1}(x)>0$, we first derivate $H_{p+1}(x)$, which is equal to $H_{p}(x)$. According to the proposition equation (A10), $H_{p}(x)$ is always positive when $x>0 . H_{p+1}(x)$ is thus a monotonically increasing function. As $H_{p+1}(0)=1, \forall x>0, H_{p+1}(x)>0$.

Now that we verified that the proposition equation (A10) is true, for a given $\alpha$ in equation (A7), we chose an integer $p$ such that $p>\alpha$ and define the $g$ function as $g(x)=\frac{p !}{x^{p-\alpha}}$.

Using the Squeeze lemma, it becomes clear that $\lim _{x \rightarrow+\infty} f(x)=0$. Hence, the whole equation (A6) reduces to

$$
\tilde{F}_{N+1}(v)=\frac{1}{(2 \pi i v+s)} \int_{0}^{+\infty} \frac{t^{N}}{N !} e^{-(2 \pi i v+s) t} \mathrm{~d} t=\frac{1}{(2 \pi i v+s)} \tilde{F}_{N}(v)
$$

Meaning

$$
\tilde{F}_{N+1}(v)=\frac{1}{(2 \pi i v+s)^{N+2}} \quad(\mathrm{QED}),
$$

which demonstrates the heredity holds and that $\mathrm{A} 3$ is verified.

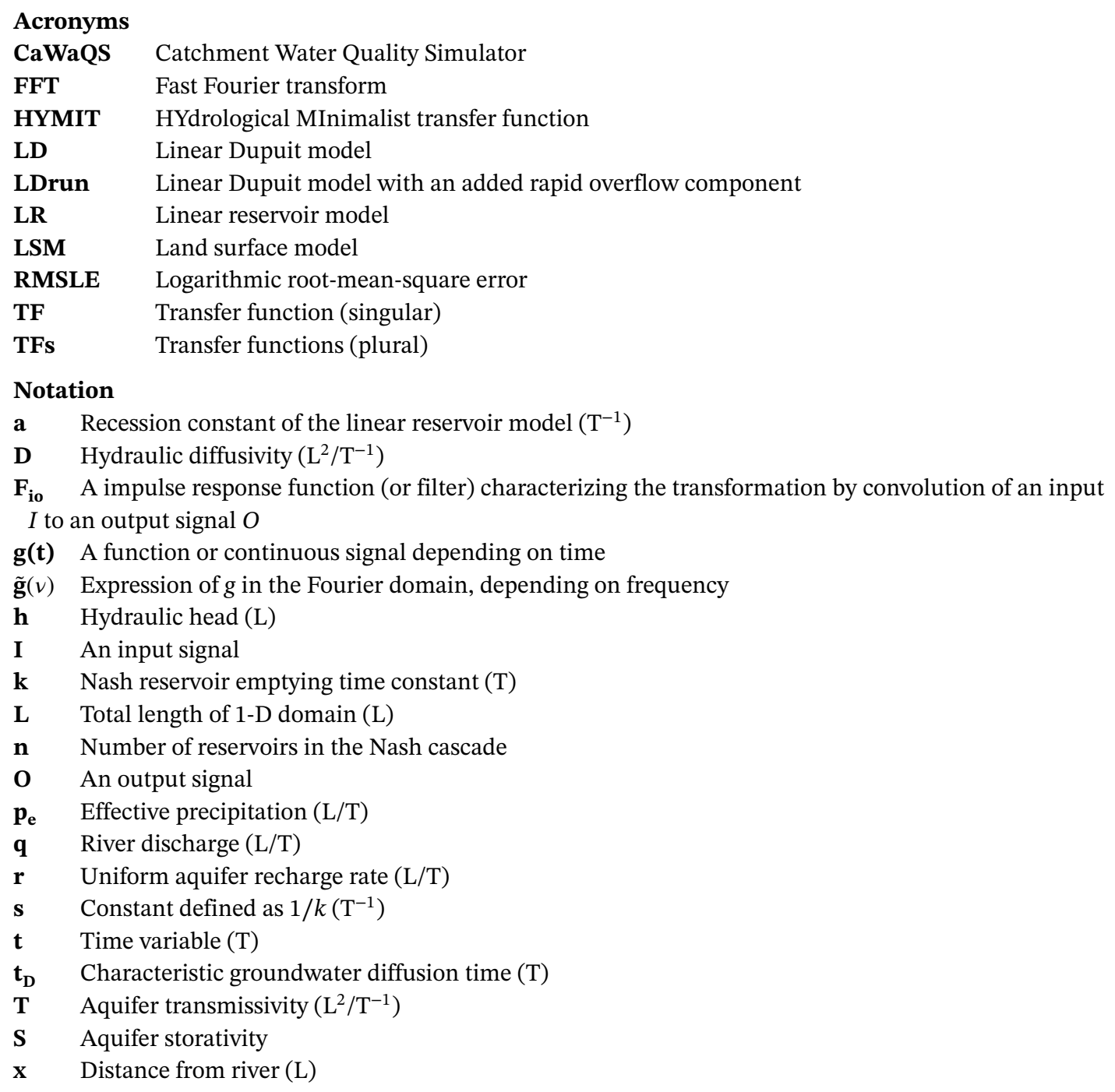


$\boldsymbol{\beta} \quad$ Fraction of diffuse overflow in the HYMIT model, and direct overflow in the Molénat model

$\Theta_{\mathrm{rh}} \quad$ Impulse response function of recharge to hydraulic head in the linear reservoir model

$\Theta_{\mathrm{rq}} \quad$ Impulse response function of recharge to discharge in the linear reservoir model

$\lambda \quad$ Recession coefficient of the diffuse overflow $\left(\mathrm{T}^{-1}\right)$

$v \quad$ Frequency $\left(\mathrm{T}^{-1}\right)$

$v_{\mathbf{c}} \quad$ Characteristic frequency defined as $1 / t_{D}\left(\mathrm{~T}^{-1}\right)$

$\boldsymbol{\Phi}$ Impulse response function of the unsaturated zone

$\chi_{\mathbf{p h}}$ Impulse response function of effective rainfall to hydraulic head in the HYMIT model

$\chi_{\mathbf{p q}} \quad$ Impulse response function of effective rainfall to discharge in the HYMIT model

$\Psi_{\mathbf{r h}}$ Impulse response function of recharge to hydraulic head in the linear Dupuit model

$\mathbf{\Omega} \quad$ Impulse response function of diffuse surface flow

\section{Acknowledgments}

This work is part of the Aquivar project funded by the French Seine-Normandy Water Agency (AESN). It is also a contribution to the PIREN-Seine research program and the CNES-TOSCA SWOT project. River discharge data are provided by Banque Hydro (http://hydro.eaufrance.fr/), a service coordinated by the French Ministry of Ecology, Sustainable Development and Energy. Well data are obtained from ADES (http://www. ades.eaufrance.fr/), coordinated by the French Geological Survey (BRGM). The BRGM also provided the lithological map in Figure 7 (BDLISA; https://bdlisa.eaufrance.fr/). We warmly thank these entities for their support. Numerous comments and suggestions made by four anonymous reviewers and the Assistant Editor considerably helped us to improve the presentation of our work. We thank them for their useful contributions. Finally, we thank Alin Bostan for fruitful discussions on the mathematical proof provided in Appendix A. The authors declare no conflict of interest.

\section{References}

Baratelli, F., Flipo, N., \& Moatar, F. (2016). Estimation of stream-aquifer exchanges at regional scale using a distributed model: Sensitivity to in-stream water level fluctuations, riverbed elevation and roughness. Journal of Hydrology, 542, 686-703.

Barco, J., Hogue, T. S., Girotto, M., Kendall, D. R., \& Putti, M. (2010). Climate signal propagation in southern California aquifers. Water Resources Research, 46, W00F05. https://doi.org/10.1029/2009WR008376

Besbes, M., \& De Marsily, G. (1984). From infiltration to recharge: Use of a parametric transfer function. Journal of Hydrology, 74(3-4), 271-293.

Beven, K. (2006). A manifesto for the equifinality thesis. Journal of Hydrology, 320(1-2), 18-36

Billen, G., Garnier, J., Mouchel, J. M., \& Silvestre, M. (2007). The Seine system: Introduction to a multidisciplinary approach of the functioning of a regional river system. Science of the Total Environment, 375(1-3), 1-12.

Blank, D., Delleur, J., \& Giorgini, A. (1971). Oscillatory kernel functions in linear hydrologic models. Water Resources Research, 7(5), 1102-1117.

Blöschl, G. (2001). Scaling in hydrology. Hydrological Processes, 15(4), 709-711.

Bouchez, J., Moquet, J. S., Espinoza, J. C., Martinez, J. M., Guyot, J. L., Lagane, C., \& Pombosa, R. (2017). River mixing in the Amazon as a driver of concentration-discharge relationships. Water Resources Research, 53, 8660-8685. https://doi.org/10.1002/2017wr020591

Cao, G., Scanlon, B. R., Han, D., \& Zheng, C. (2016). Impacts of thickening unsaturated zone on groundwater recharge in the North China Plain. Journal of Hydrology, 537, 260-270.

Chevalier, L., Laignel, B., Massei, N., Munier, S., Becker, M., Turki, I., \& Cazenave, A. (2014). Hydrological variability of major French rivers over recent decades, assessed from gauging station and GRACE observations. Hydrological Sciences Journal, 59(10), $1844-1855$.

Cloke, H. L., \& Hannah, D. M. (2011). Large-scale hydrology: Advances in understanding processes, dynamics and models from beyond river basin to global scale. Hydrological Processes, 25(7), 991-995.

Collischonn, W., Allasia, D., Da Silva, B. C., \& Tucci, C. E. (2007). The MGB-IPH model for large-scale rainfall-runoff modelling. Hydrological Sciences Journal, 52(5), 878-895.

David, C. H., Habets, F., Maidment, D. R., \& Yang, Z. L. (2011). RAPID applied to the SIM-France model. Hydrological Processes, 25(22), $3412-3425$.

Devia, G. K., Ganasri, B., \& Dwarakish, G. (2015). A review on hydrological models. Aquatic Procedia, 4, 1001-1007.

Dooge, J. (1968). The hydrologic cycle as a closed system. International Association of Scientific Hydrology. Bulletin, 13(1), 58-68.

Ducharne, A., Baubion, C., Beaudoin, N., Benoit, M., Billen, G., Brisson, N., \& Viennot, P. (2007). Long term prospective of the Seine River system: Confronting climatic and direct anthropogenic changes. Science of The Total Environment, 375(1), $292-311$.

Ducharne, A., Golaz, C., Leblois, E., Laval, K., Polcher, J., Ledoux, E., \& de Marsily, G. (2003). Development of a high resolution runoff routing model, calibration and application to assess runoff from the LMD GCM. Journal of Hydrology, 280(1-4), 207-228.

Fatichi, S., Vivoni, E. R., Ogden, F. L., Ivanov, V. Y., Mirus, B., Gochis, D., \& Tarboton, D. (2016). An overview of current applications, challenges, and future trends in distributed process-based models in hydrology. Journal of Hydrology, 537, 45-60. https://doi.org/10. 1016/j.jhydrol.2016.03.026

Flipo, N., Monteil, C., Poulin, M., Fouquet, C., \& Krimissa, M. (2012). Hybrid fitting of a hydrosystem model: Long-term insight into the Beauce aquifer functioning (France). Water Resources Research, 48, W05509. https://doi.org/10.1029/2011WR011092

Flipo, N., Mouhri, A., Labarthe, B., Biancamaria, S., Rivière, A., \& Weill, P. (2014). Continental hydrosystem modelling: The concept of nested stream-aquifer interfaces. Hydrology and Earth System Sciences, 18(8), 3121-3149. https://doi.org/10.5194/hess-18-3121-2014

Floury, P., Gaillardet, J., Gayer, E., Bouchez, J., Tallec, G., Ansart, P., \& Roubaty, J. L. (2017). The potamochemical symphony: New progress in the high-frequency acquisition of stream chemical data. Hydrology and Earth System Sciences, 21(12), 6153-6165.

Floury, P., Gaillardet, J., Tallec, G., Ansart, P., Bouchez, J., Louvat, P., \& Gorge, C. (2018). Chemical weathering and $\mathrm{CO}_{2}$ consumption rate in a multilayered-aquifer dominated watershed under intensive farming: The Orgeval Critical Zone Observatory, France. Hydrological Processes, 33, 195-213. https://doi.org/10.1002/hyp.13340

Gelhar, L. (1974). Stochastic analysis of phreatic aquifers. Water Resources Research, 10(3), 539-545.

Gelhar, L. W., \& Wilson, J. L. (1974). Ground-water quality modeling. Groundwater, 12(6), 399-408.

Grathwohl, P., Rügner, H., Wöhling, T., Osenbrück, K., Schwientek, M., Gayler, S., et al. (2013). Catchments as reactors: A comprehensive approach for water fluxes and solute turnover. Environmental Earth Sciences, 69(2), 317-333.

Gupta, H. V., Beven, K. J., \& Wagener, T. (2005). Model calibration and uncertainty estimation. In M. G. Anderson (Ed.), Encyclopedia of Hydrological Sciences (pp. 2015-2031). New York: Wiley.

Gupta, H. V., Kling, H., Yilmaz, K. K., \& Martinez, G. F. (2009). Decomposition of the mean squared error and NSE performance criteria: Implications for improving hydrological modelling. Journal of Hydrology, 377(1-2), 80-91.

Harris, F. J. (1978). On the use of windows for harmonic analysis with the discrete Fourier transform. Proceedings of the IEEE, 66(1), 51-83.

Harter, T., \& Hopmans, J. W. (2004). Role of vadose-zone flow processes in regional scale hydrology: Review, opportunities and challenges. In F. R. A. de Rooij \& J. C. Van Dam (Eds.), Unsaturated-zone modeling (pp. 179-208). The Netherlands: Kluwer, Dordrecht. 
Jakeman, A., \& Hornberger, G. (1993). How much complexity is warranted in a rainfall-runoff model? Water Resources Research, 29(8), 2637-2649.

Jiménez-Martínez, J., Longuevergne, L., Le Borgne, T., Davy, P., Russian, A., \& Bour, O. (2013). Temporal and spatial scaling of hydraulic response to recharge in fractured aquifers: Insights from a frequency domain analysis. Water Resources Research, 49, 3007-3023. https:// doi.org/10.1002/wrcr.20260

Jiménez-Martínez, J., Smith, M., \& Pope, D. (2016). Prediction of groundwater-induced flooding in a chalk aquifer for future climate change scenarios. Hydrological Processes, 30(4), 573-587.

Kirchner, J. W., Feng, X., \& Neal, C. (2000). Fractal stream chemistry and its implications for contaminant transport in catchments. Nature, 403(6769), 524

Kirchner, J. W., Feng, X., \& Neal, C. (2001). Catchment-scale advection and dispersion as a mechanism for fractal scaling in stream tracer concentrations. Journal of Hydrology, 254(1), 82-101. https://doi.org/10.1016/S0022-1694(01)00487-5

Krinner, G., Viovy, N., de Noblet-Ducoudré, N., Ogée, J., Polcher, J., Friedlingstein, P., \& Prentice, I. C. (2005). A dynamic global vegetation model for studies of the coupled atmosphere-biosphere system. Global Biogeochemical Cycles, 19, GB1015. https://doi.org/10.1029/ 2003GB002199

Labat, D., Ababou, R., \& Mangin, A. (2000). Rainfall-runoff relations for karstic springs. Part I: Convolution and spectral analyses. Journal of Hydrology, 238(3-4), 123-148.

Labat, D., Mangin, A., \& Ababou, R. (2002). Rainfall-runoff relations for karstic springs: Multifractal analyses. Journal of Hydrology, 256(3-4), 176-195

Ledoux, E., Girard, G., \& Villeneuve, J. (1984). Proposition d'un modèle couplé pour la simulation conjointe des écoulements de surface et des écoulements souterrains sur un bassin hydrologique. La houille blanche, 1-2, 101-120.

Liang, X., Lettenmaier, D. P., Wood, E. F., \& Burges, S. J. (1994). A simple hydrologically based model of land surface water and energy fluxes for general circulation models. Journal of Geophysical Research, 99(D7), 14,415-14,428.

Liang, X., Wood, E. F., \& Lettenmaier, D. P. (1996). Surface soil moisture parameterization of the VIC-2L model: Evaluation and modification. Global and Planetary Change, 13(1-4), 195-206.

Long, A., \& Derickson, R. (1999). Linear systems analysis in a Karst aquifer. Journal of Hydrology, 219(3-4), $206-217$.

Manga, M. (1999). On the timescales characterizing groundwater discharge at springs. Journal of Hydrology, 219(1-2), 56-69.

Massei, N., Dieppois, B., Hannah, D., Lavers, D., Fossa, M., Laignel, B., \& Debret, M. (2017). Multi-time-scale hydroclimate dynamics of a regional watershed and links to large-scale atmospheric circulation: Application to the Seine river catchment, France. Journal of Hydrology, 546, 262-275.

Massei, N., \& Fournier, M. (2012). Assessing the expression of large-scale climatic fluctuations in the hydrological variability of daily Seine river flow (France) between 1950 and 2008 using Hilbert-Huang Transform. Journal of Hydrology, 448-449, 119-128.

Massei, N., Laignel, B., Deloffre, J., Mesquita, J., Motelay, A., Lafite, R., \& Durand, A. (2010). Long-term hydrological changes of the Seine River flow (France) and their relation to the North Atlantic Oscillation over the period 1950-2008. International journal of Climatology, 30(14), 2146-2154.

Masson, V., Le Moigne, P., Martin, E., Faroux, S., Alias, A., Alkama, R., et al. (2013). The SURFEXv7. 2 land and ocean surface platform for coupled or offline simulation of Earth surface variables and fluxes. Geoscientific Model Development, 6, 929-960.

Matsoukas, C., Islam, S., \& Rodriguez-Iturbe, I. (2000). Detrended fluctuation analysis of rainfall and streamflow time series. Journal of Geophysical Research, 105(D23), 29,165-29,172.

McGuire, K. J., \& McDonnell, J. J. (2006). A review and evaluation of catchment transit time modeling. Journal of Hydrology, 330(3), 543-563. https://doi.org/10.1016/j.jhydrol.2006.04.020

Milly, P. (1994). Climate, interseasonal storage of soil water, and the annual water balance. Advances in Water Resources, 17(1-2), 19-24.

Molénat, J., Davy, P., Gascuel-Odoux, C., \& Durand, P. (1999). Study of three subsurface hydrologic systems based on spectral and cross-spectral analysis of time series. Journal of Hydrology, 222(1-4), 152-164.

Montanari, A., \& Toth, E. (2007). Calibration of hydrological models in the spectral domain: An opportunity for scarcely gauged basins? Water Resources Research, 43, W05434. https://doi.org/10.1029/2006WR005184

Morel-Seytoux, H. J. (2009). The turning factor in the estimation of stream-aquifer seepage. Groundwater, 47(2), $205-212$.

Nash, J. (1959). Systematic determination of unit hydrograph parameters. Journal of Geophysical Research, 64(1), 111-115.

Nash, J. E., \& Sutcliffe, J. V. (1970). River flow forecasting through conceptual models. Part I-A discussion of principles. Journal of hydrology, 10(3), 282-290.

Neuman, S. P., \& De Marsily, G. (1976). Identification of linear systems response by parametric programming. Water Resources Research, 12(2), 253-262.

Olsthoorn, T. N. (2008). Do a bit more with convolution. Groundwater, 46(1), 13-22.

Paiva, R. C. D., Buarque, D. C., Collischonn, W., Bonnet, M. P., Frappart, F., Calmant, S., \& Mendes, C. A. B. (2013). Large-scale hydrologic and hydrodynamic modeling of the Amazon River basin. Water Resources Research, 49, 1226-1243. https://doi.org/10.1002/wrcr.20067

Pedretti, D., Russian, A., Sanchez-Vila, X., \& Dentz, M. (2016). Scale dependence of the hydraulic properties of a fractured aquifer estimated using transfer functions. Water Resources Research, 52, 5008-5024. https://doi.org/10.1002/2016WR018660

Pitman, A. (2003). The evolution of, and revolution in, land surface schemes designed for climate models. International Journal of Climatology, 23(5), 479-510.

Priestley, H. A. (2003). Introduction to complex analysis. Oxford, UK: Oxford University Press Inc.

Pryet, A., Labarthe, B., Saleh, F., Akopian, M., \& Flipo, N. (2015). Reporting of stream-aquifer flow distribution at the regional scale with a distributed process-based model. Water Resources Management, 29(1), 139-159.

Quintana-Segui, P., Le Moigne, P., Durand, Y., Martin, E., Habets, F., Baillon, M., \& Morel, S. (2008). Analysis of near-surface atmospheric variables: Validation of the SAFRAN analysis over France. Journal of Applied Meteorology and Climatology, 47(1), 92-107.

Russian, A., Dentz, M., Le Borgne, T., Carrera, J., \& Jimenez-Martinez, J. (2013). Temporal scaling of groundwater discharge in dual and multicontinuum catchment models. Water Resources Research, 49, 8552-8564. https://doi.org/10.1002/2013WR014255

Saleh, F., Flipo, N., Habets, F., Ducharne, A., Oudin, L., Viennot, P., \& Ledoux, E. (2011). Modeling the impact of in-stream water level fluctuations on stream-aquifer interactions at the regional scale. Journal of Hydrology, 400(3-4), 490-500.

Samaniego, L., Kumar, R., \& Attinger, S. (2010). Multiscale parameter regionalization of a grid-based hydrologic model at the mesoscale. Water Resources Research, 46, W05523. https://doi.org/10.1029/2008WR007327

Schilling, K. E., \& Zhang, Y. K. (2012). Temporal scaling of groundwater level fluctuations near a stream. Groundwater, 50(1), 59-67.

Slimani, S., Massei, N., Mesquita, J., Valdés, D., Fournier, M., Laignel, B., \& Dupont, J. P. (2009). Combined climatic and geological forcings on the spatio-temporal variability of piezometric levels in the chalk aquifer of Upper Normandy (France) at pluridecennal scale. Hydrogeology Journal, 17(8), 1823. 
Weiler, M., McGlynn, L., McGuire, J., \& McDonnell, J. (2003). How does rainfall become runoff? A combined tracer and runoff transfer function approach. Water Resources Research, 39(11), 1315. https://doi.org/10.1029/2003WR002331

Welch, P. (1967). The use of fast Fourier transform for the estimation of power spectra: A method based on time averaging over short, modified periodograms. IEEE Transactions on Audio and Electroacoustics, 15(2), 70-73.

Wu, H., Adler, R. F., Tian, Y., Huffman, G. J., Li, H., \& Wang, J. (2014). Real-time global flood estimation using satellite-based precipitation and a coupled land surface and routing model. Water Resources Research, 50, 2693-2717. https://doi.org/10.1002/2013WR014710

Wu, J., Zhang, R., \& Yang, J. (1997). Estimating infiltration recharge using a response function model. Journal of Hydrology, 198(1-4), 124-139.

Zhang, Y. K., \& Schilling, K. (2004). Temporal scaling of hydraulic head and river base flow and its implication for groundwater recharge. Water Resources Research, 40, W03504. https://doi.org/10.1029/2003WR002094 